\title{
Effects of Soya Oil upon the Metabolic Syndrome of $\omega 3$-Depleted Rats
}

\author{
Willy J. Malaisse and Yvon A. Carpentier \\ Laboratories of Experimental Hormonology and Surgery, \\ Université Libre de Bruxelles, Brussels, \\ Belgium
}

\section{Introduction}

The bolus intravenous injection of a novel medium-chain triglyceride:fish oil emulsion was recently proposed as a suitable tool to increase within $60 \mathrm{~min}$ the long-chain polyunsaturated $\omega 3$ fatty acid content of cell phospholipids (Carpentier et al., 2010). The optimal procedure for the dietary correction of the metabolic and hormonal perturbations found in situations of $\omega 3$-depletion, in terms of the total lipid content and source of $\omega 3$ fatty acids in the diet, as well as the time course for the enrichment of tissue lipids in these $\omega 3$ fatty acids, merits, however, further attention (Malaisse et al., 2011). In such a perspective, the present report deals mainly with the possible suitability of a diet containing $5 \%(\mathrm{w} / \mathrm{w})$ soya oil, as assessed in rats first exposed for 3 months to an $\omega 3$-deficient sunflower oil (also $5 \%)$ diet.

\section{Materials and methods}

Six groups of 4 fed female rats each were examined in the present study. Two groups consisted of control animals exposed from the age of 8 weeks after birth for 3 months to a diet containing $5 \%(\mathrm{w} / \mathrm{w})$ soya oil and examined either at the end of this 3 months initial period or 8 weeks later whilst being maintained on the soya oil diet. The other 4 groups of rats were first exposed during the initial 3 months period to a diet containing $5 \%(\mathrm{w} / \mathrm{w})$ sunflower oil ( $\omega 3 \mathrm{D}$ rats) and examined either at the end of this 3 months initial period or after further exposure for one, two or eight weeks to the soya oil diet. Six further $\omega 3 \mathrm{D}$ rats were maintained after the end of the initial 3 months period and for the ensuing 8 weeks to the sunflower oil diet, but were only examined for their food intake and body weight. The rats were eventually sacrificed by $\mathrm{CO}_{2}$ inhalation. The methods used for collection of intestinal mucosa at the jejunal and caecal level (Hacquebard et al., 2009), liver (Malaisse et al., 2009), red blood cell (Carpentier et al., 2011a), brain (Portois et al., 2009) and both visceral and parametrial adipose tissue (Portois et al., 2007) sampling, lipid extraction (Folch et al., 1957), separation by thin-layer chromatography (Dahlan et al., 1992) and determination of lipid fatty acid pattern by gas-liquid chromatography (Lepage \& Roy, 1986), food intake measurements (Zhang et al., 2010) and plasma D-glucose (Lowry \& Passonneau, 1972) and insulin (Leclercq-Meyer et al., 1985) determinations were previously described in the cited references. 
All results are presented as mean values $( \pm$ SEM) together with the number of individual observations (n) or degree of freedom (df). Except if otherwise mentioned, all tabulated values refer to four individual determinations. In the case of $\mathrm{RBC}$, however, the measurements listed for $\omega 3 \mathrm{D}$ rats examined 1 or 2 weeks after the switch in diet refer to single measurements made in pooled material from 4 rats. In the Tables, the indication N.T. refers to non-tabulated data. The statistical significance of differences between mean values was assessed by use of Student's $t$-test.

\section{Results}

\subsection{Fatty acid pattern of intestinal phospholipids}

\subsubsection{Long-chain polyunsaturated $\omega 3$ fatty acids}

At the end of the 3 months initial period, the relative weight content of all $\omega 3$ fatty acids

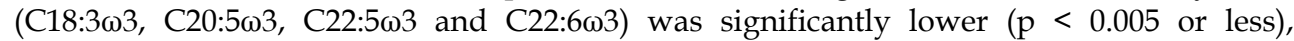
whether in the jejunum or caecum, in the $\omega 3 \mathrm{D}$ rats than in the control animals (Table 1). When the former rats were then exposed for one week to the soya oil diet, a significant increase ( $\mathrm{p}<0.02$ or less) in the $\mathrm{C} 18: 3 \omega 3, \mathrm{C} 22: 5 \omega 3$ and $\mathrm{C} 22: 6 \omega 3$ relative content of jejunal phospholipids and in the $\mathrm{C} 22: 5 \omega 3$ and $\mathrm{C} 22: 6 \omega 3$ content of caecal phospholipids was observed, whilst such was not the case for either the C20:5 13 content of jejunal

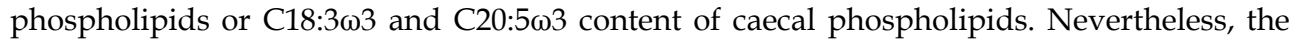
mean values reached in the $\omega 3 \mathrm{D}$ rats exposed for one week to the soya oil remained, as a rule, lower than those found in the control animals at the end of the 3 months initial period. Even, in the two out of eight instances in which such was not the case, i.e. for the C18:3 13 content of jejunal phospholipids and C22:5 $\omega 3$ content of caecal phospholipids, no significant difference ( $p>0.3$ or more) was found between the two groups of rats under consideration.

\begin{tabular}{|c|c|c|c|c|c|}
\hline Rats & & $\mathrm{C} 18: 3 \omega 3$ & $\mathrm{C} 20: 5 \omega 3$ & $\mathrm{C} 22: 5 \omega 3$ & $\mathrm{C} 22: 6 \omega 3$ \\
\hline \multicolumn{6}{|c|}{ Jejunum } \\
\hline Control & before & $7.10 \pm 1.46$ & $0.00 \pm 0.00$ & $4.18 \pm 0.39$ & $39.51 \pm 2.00$ \\
\hline \multirow[t]{2}{*}{$\omega 3 \mathrm{D}$} & before & $0.00 \pm 0.00$ & $0.00 \pm 0.00$ & $0.00 \pm 0.00$ & $14.86 \pm 1.62$ \\
\hline & after (1 wk) & $8.30 \pm 1.35$ & $0.42 \pm 0.42$ & $2.89 \pm 0.32$ & $25.88 \pm 2.18$ \\
\hline \multicolumn{6}{|c|}{ Caecum } \\
\hline Control & before & $1.46 \pm 1.46$ & $2.76 \pm 1.60$ & $2.74 \pm 2.74$ & $49.94 \pm 6.83$ \\
\hline \multirow[t]{2}{*}{$\omega 3 \mathrm{D}$} & before & $0.00 \pm 0.00$ & $0.00 \pm 0.00$ & $0.00 \pm 0.00$ & $5.49 \pm 5.49$ \\
\hline & after (1 wk) & $0.00 \pm 0.00$ & $0.00 \pm 0.00$ & $5.60 \pm 0.65$ & $23.80 \pm 1.57$ \\
\hline
\end{tabular}

Table 1. Relative weight content (\%o) of long-chain polyunsaturated $\omega 3$ fatty acids in jejunum and caecum phospholipids

\subsubsection{Long-chain polyunsaturated $\omega 6$ fatty acids}

As shown in Table 2, no significant difference between the three groups of rats was

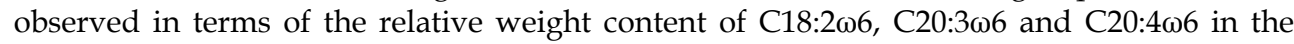

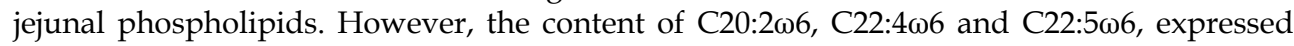
relative to their respective overall mean values averaged $38.2 \pm 12.0 \%(n=12)$ in the control animals examined at the end of the 3 months initial period, as distinct $(p<0.001)$ from 166.2 
$\pm 17.6 \%(n=12)$ in the $\omega 3 \mathrm{D}$ rats examined before the switch in diet. After one week exposure to the soya oil diet, the latter percentage was decreased $(p<0.005)$ to $95.6 \pm 8.4 \%(n=12)$, the latter value remaining higher $(\mathrm{p}<0.001)$ than that recorded in the control animals.

The relative weight content of $\omega 6$ fatty acids differed, on occasion, in the jejunal versus caecal phospholipids. For instance, the weight content of C18:2 $\omega 6$ averaged $320.88 \pm 9.60 \%$ o $(n=12)$ at the jejunal level, as distinct $(\mathrm{p}<0.001)$ from only $187.42 \pm 5.53 \%$ o $(\mathrm{n}=12)$ at the caecal level. Moreover, as a rule, no significant difference between the mean values recorded in the three groups of rats was observed for the relative weight content of $\omega 6$ fatty acids in the caecal phospholipids. Only in the case of $C 22: 5 \omega 6$, a significant increase $(p<0.001)$ in the content of this fatty acid in caecal phospholipids was found when comparing control animals and $\omega 3 \mathrm{D}$ rats both examined at the end of the 3 months initial period, with an inbetween value ( $p<0.01$ or less) in the $\omega 3 \mathrm{D}$ rats examined one week after the switch in diet.

\begin{tabular}{|c|c|c|c|c|c|c|}
\hline Rats & & $\mathrm{C} 18: 2 \omega 6$ & $\mathrm{C} 20: 2 \omega 6$ & 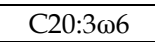 & 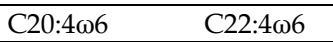 & $\mathrm{C} 22: 5 \omega 6$ \\
\hline \multicolumn{7}{|c|}{ Jejunum } \\
\hline Control & before & $314.40 \pm 19.28$ & $1.16 \pm 0.68$ & $5.71 \pm 0.45$ & $175.68 \pm 21.414 .24 \pm 0.60$ & $0.00 \pm 0.00$ \\
\hline \multirow{2}{*}{$\omega 3 \mathrm{D}$} & before & $316.85 \pm 16.43$ & $4.61 \pm 0.71$ & $6.31 \pm 0.75$ & $173.77 \pm 8.19 \quad 7.94 \pm 1.66$ & $16.80 \pm 3.09$ \\
\hline & after (1 wk) & $331.38 \pm 17.79$ & $2.87 \pm 0.41$ & $4.94 \pm 0.58$ & $167.09 \pm 11.114 .94 \pm 0.39$ & $8.48 \pm 1.84$ \\
\hline \multicolumn{7}{|c|}{ Caecum } \\
\hline \multirow{3}{*}{$\begin{array}{l}\text { Control } \\
\omega 3 \mathrm{D}\end{array}$} & before & $192.02 \pm 12.80$ & $3.40 \pm 1.96$ & $\overline{16.50 \pm 0.36}$ & $164.85 \pm 12.0416 .69 \pm 5.70$ & $2.13 \pm 1.32$ \\
\hline & before & $189.76 \pm 8.28$ & $0.00 \pm 0.00$ & $7.42 \pm 4.34$ & $200.00 \pm 13.1329 .56 \pm 3.28$ & $26.47 \pm 1.37$ \\
\hline & after (1 wk) & $180.50 \pm 8.92$ & $3.66 \pm 2.12$ & $16.59 \pm 0.62$ & $214.29 \pm 10.2124 .39 \pm 1.05$ & $16.12 \pm 2.25$ \\
\hline
\end{tabular}

Table 2. Relative weight content (\%o) of long-chain polyunsaturated $\omega 6$ fatty acids in jejunum and caecum phospholipids

\subsubsection{Saturated fatty acids}

The relative weight content of saturated fatty acids often differed significantly in jejunal versus caecal phospholipids (Table 3 ). For instance, the C14:0 content was close to 15-fold higher $(\mathrm{p}<0.001)$ in the caecal phospholipids $(9.44 \pm 1.13 \%$; $n=12)$ than in the jejunal phospholipids $(0.64 \pm 0.23 \%$; $n=12)$. Whether at the jejunal or caecal level, no significant difference was observed between the relative weight content of a given saturated fatty acid in the three groups of rats under consideration.

\begin{tabular}{llllllll}
\hline Rats & & C14:0 & C16:0 & C18:0 & C20:0 & C22:0 & C24:0 \\
\hline \multirow{7}{*}{$\begin{array}{c}\text { Control } \\
\omega 3 D\end{array}$} & before & $0.00 \pm 0.00$ & $167.22 \pm 3.42$ & $198.25 \pm 9.42$ & $7.00 \pm 0.79$ & $7.58 \pm 0.53$ & $6.25 \pm 0.51$ \\
& before & $0.78 \pm 0.45$ & $164.31 \pm 10.29$ & $204.77 \pm 5.02$ & $9.32 \pm 3.02$ & $10.83 \pm 2.73$ & $9.24 \pm 2.38$ \\
& after (1 wk) & $1.15 \pm 0.39$ & $160.78 \pm 4.72$ & $198.89 \pm 6.32$ & $7.30 \pm 0.60$ & $8.33 \pm 0.69$ & $8.43 \pm 0.99$ \\
\hline \multirow{7}{c}{$\begin{array}{c}\text { Caecum } \\
\text { Control }\end{array}$} & before & $7.79 \pm 3.03$ & $247.74 \pm 15.67$ & $123.27 \pm 10.61$ & $15.05 \pm 3.28$ & $18.09 \pm 5.06$ & $18.20 \pm 7.70$ \\
$\omega 3 \mathrm{D}$ & before & $9.01 \pm 0.69$ & $242.60 \pm 10.81$ & $129.05 \pm 4.07$ & $11.83 \pm 2.12$ & $12.85 \pm 2.12$ & $9.61 \pm 1.39$ \\
& after (1 wk) & $11.51 \pm 1.38$ & $233.53 \pm 12.15$ & $120.62 \pm 4.78$ & $10.55 \pm 1.18$ & $10.11 \pm 1.24$ & $7.98 \pm 1.50$ \\
\hline
\end{tabular}

Table 3. Relative weight content (\%o) of saturated fatty acids in jejunum and caecum phospholipids

\subsubsection{Monodesaturated fatty acids}

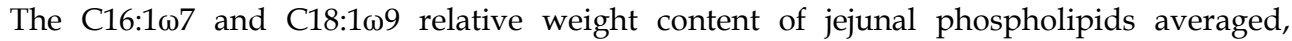
respectively, $2.97 \pm 0.39 \%$ and $60.66 \pm 2.82 \%$ o $(n=12$ in both cases), as distinct ( $p<0.001)$ 
from $10.01 \pm 1.56 \%$ ond $117.51 \pm 2.01 \%$ o $(n=12$ in both cases) in caecal phospholipids. Such contents failed to differ significantly from one another, whether in the jejunum or caecum, in the three groups of rats under consideration (Table 4). A sizeable amount of C20:1 $\omega 9$ in intestinal phospholipids was only detected in one out of 4 rats in the $\omega 3 \mathrm{D}$ rats examined before or after the switch in diet. No C22:1 $\omega 9$ could be detected in any of the 24 rats examined for such a purpose.

\begin{tabular}{|c|c|c|c|c|c|}
\hline Rats & & $\mathrm{C} 16: 1 \omega 7$ & 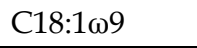 & 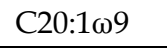 & 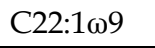 \\
\hline \multicolumn{6}{|c|}{ Jejunum } \\
\hline Control & before & $3.70 \pm 0.70$ & $58.03 \pm 2.03$ & $0.00 \pm 0.00$ & $0.00 \pm 0.00$ \\
\hline \multirow[t]{2}{*}{$\omega 3 \mathrm{D}$} & before & $2.50 \pm 0.92$ & $64.77 \pm 2.11$ & $0.43 \pm 0.43$ & $0.00 \pm 0.00$ \\
\hline & after (1 wk) & $2.71 \pm 0.20$ & $59.18 \pm 3.94$ & $0.05 \pm 0.05$ & $0.00 \pm 0.00$ \\
\hline \multicolumn{6}{|c|}{ Caecum } \\
\hline Control & before & $5.54 \pm 3.34$ & $120.28 \pm 1.42$ & $0.00 \pm 0.00$ & $0.00 \pm 0.00$ \\
\hline \multirow[t]{2}{*}{$\omega 3 \mathrm{D}$} & before & $12.18 \pm 2.09$ & $118.44 \pm 4.76$ & $1.01 \pm 1.01$ & $0.00 \pm 0.00$ \\
\hline & after (1 wk) & $12.30 \pm 1.17$ & $113.82 \pm 3.49$ & $0.91 \pm 0.91$ & $0.00 \pm 0.00$ \\
\hline
\end{tabular}

Table 4. Relative weight content (\%o) of monodesaturated fatty acids in jejunum and caecum phospholipids

\subsection{Relation between intestinal and hepatic phospholipids}

In the case of long-chain polyunsaturated $\omega 3$ fatty acids, highly significant positive correlations prevailed between the relative content of $\mathrm{C} 18: 3 \omega 3$ in jejunal and hepatic phospholipids $(\mathrm{r}=+0.8368 ; \mathrm{n}=12 ; \mathrm{p}<0.001)$, that of $\mathrm{C} 22: 5 \omega 3$ also in jejunal and hepatic phospholipids $(\mathrm{r}=+0.9153 ; \mathrm{n}=12 ; \mathrm{p}<0.001)$, and that of $\mathrm{C} 22: 6 \omega 3$ either in jejunal and hepatic phospholipids $(\mathrm{r}=+0.9716 ; \mathrm{n}=12 ; \mathrm{p}<0.001)$ or in caecal and hepatic phospholipids $(\mathrm{r}=+0.8679 ; \mathrm{n}=12 ; \mathrm{p}<0.001)$. The paired ratio between the C22:6 $\omega 3$ relative weight content in hepatic/jejunal phospholipids did not differ significantly ( $p>0.14$ or more) in the three groups of rats under consideration, i.e. control and $\omega 3 \mathrm{D}$ rats examined at the end of the 3 months initial period and $\omega 3 \mathrm{D}$ rats exposed for one week to the soya oil diet, with an overall mean value of $4.13 \pm 0.16(n=12)$.

In the case of long-chain polyunsaturated $\omega 6$ fatty acids, a significant positive correlation $(\mathrm{r}=+0.5868 ; \mathrm{n}=12 ; \mathrm{p}<0.05)$ was found between the $\mathrm{C} 22: 4 \omega 6$ relative weight content of jejunal and hepatic phospholipids in the same 12 rats. Such was not the case $(r=+0.4924 ; n$ $=12 ; \mathrm{p}>0.1)$ for the C20:2 $\omega 6$ content of the same phospholipids. The tightest correlations concerned the C22:5 $\omega 6$ or liver phospholipids and that of either jejunal phospholipids $(\mathrm{r}=+$ 0.9776; $\mathrm{n}=12 ; \mathrm{p}<0.001)$ or caecal phospholipids $(\mathrm{r}=+0.9242 ; \mathrm{n}=12 ; \mathrm{p}<0.001)$, with, in the latter two series of comparisons, either only one or no negative xy product among the 12 sets of data.

\subsection{Fatty acid pattern of liver phospholipids \\ 3.3.1 Long-chain polyunsaturated $\omega 3$ fatty acids}

In fair agreement with the jejunal data, the relative weight content of $\mathrm{C} 18: 3 \omega 3$ in liver phospholipids averaged at the end of the initial 3 months period $0.35 \pm 0.35 \%$ o $(n=4)$ in the 
$\omega 3 \mathrm{D}$ rats, as distinct $(\mathrm{p}<0.005)$ from $2.30 \pm 0.19 \%$ o $(\mathrm{n}=4)$ in the control animals, increasing $(\mathrm{p}<0.005)$ in the former $\omega 3 \mathrm{D}$ rats to, respectively, $1.91 \pm 0.09$ and $2.09 \pm 0.17 \%$ o $(n=4$ in both cases) one and two weeks after the switch to the soya oil diet.

The relative weight content of the three other long-chain polyunsaturated $\omega 3$ fatty acids in liver phospholipids yielded comparable information (Table 5). First, the mean values recorded in the control animals before the switch in diet and 8 weeks thereafter never differed significantly ( $p>0.6$ or more) from one another, with overall mean values of $4.99 \pm$ $0.77 \%$ o $(n=8)$ for $C 20: 5 \omega 3,9.29 \pm 0.58 \%$ o $(n=8)$ for $C 22: 5 \omega 3$ and $170.43 \pm 2.92 \%$ o $(n=8)$ for $\mathrm{C} 22: 6 \omega 3$. Second, these mean values were all significantly higher ( $p<0.002$ or less) than those recorded in the $\omega 3 \mathrm{D}$ rats at the end of the 3 months initial period. Third, in the $\omega 3 \mathrm{D}$ rats, higher values ( $p<0.025$ or less) were found after the switch in diet then before such a switch, with mean values over the 8 weeks exposure to the soya oil diet averaging $2.47 \pm$ $0.55 \%$ o $(\mathrm{n}=12)$ in the case of $\mathrm{C} 20: 5 \omega 3,7.15 \pm 0.67 \%$ o $(\mathrm{n}=12)$ in the case of C22:5 $\mathrm{\omega} 3$ and $130.02 \pm 6.80 \%$ o $(n=12)$ in the case of $C 22: 6 \omega 3$. Last, the latter three percentages all remained significantly lower ( $\mathrm{p}<0.02$ or less) than the corresponding mean values recorded in the control animals over the same period of 8 weeks. In the $\omega 3 \mathrm{D}$ rats, a progressive time-related increase in the relative weight content of a long-chain polyunsaturated $\omega 3$ fatty acid in the liver phospholipids between the first and last week of exposure to the soya oil diet was only observed in the case of $\mathrm{C} 22: 6 \omega 3(\mathrm{r}=+0.6374 ; \mathrm{n}=12 ; \mathrm{p}<0.04)$.

These findings indicate that, except as far as C18:3 103 is concerned, a period of 8 weeks exposure of the $\omega 3 \mathrm{D}$ rats to the soya oil diet was not quite sufficient to restore the liver phospholipid content of $\omega 3$ fatty acids to the same level as that otherwise found in control animals exposed to the same diet from the $8^{\text {th }}$ week after birth.

\begin{tabular}{lllll}
\hline Rats & $\mathrm{C} 20: 5 \omega 3$ & $\mathrm{C} 22: 5 \omega 3$ & $\mathrm{C} 22: 6 \omega 3$ \\
\hline Control & before & $5.05 \pm 1.12$ & $9.00 \pm 0.41$ & $169.11 \pm 4.49$ \\
& after $(8 \mathrm{wk})$ & $4.93 \pm 1.22$ & $9.58 \pm 1.17$ & $171.81 \pm 4.37$ \\
$\omega 3 \mathrm{D} \quad$ before & $0.00 \pm 0.00$ & $1.56 \pm 0.80$ & $54.52 \pm 5.32$ \\
& after $(1 \mathrm{wk})$ & $2.80 \pm 1.40$ & $6.81 \pm 1.23$ & $112.62 \pm 8.54$ \\
& after (2 wk) & $1.90 \pm 0.73$ & $5.96 \pm 0.33$ & $128.16 \pm 4.91$ \\
& after (8 wk) & $2.71 \pm 0.85$ & $8.68 \pm 1.40$ & $149.37 \pm 13.55$ \\
\hline
\end{tabular}

Table 5. Relative weight content (\%o) of long-chain polyunsaturated $\omega 3$ fatty acids in liver phospholipids

\subsubsection{Long-chain polyunsaturated $\omega 6$ fatty acids}

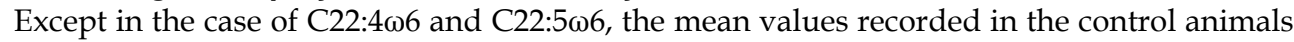
were not significantly different at the end of the 3 months initial period and 8 weeks thereafter (Table 6). In the former two cases, however, the mean values found at the end of the experiments were higher $(\mathrm{p}<0.02$ or less) than those recorded at the end of the 3 months initial period.

No significant difference between the 6 groups of rats listed in Table 6 was observed for the

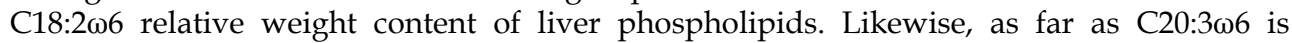
concerned, the mean value found in the control animals $(7.28 \pm 0.74 \%$; $\mathrm{n}=8)$ did not differ significantly $(\mathrm{p}>0.5)$ from that recorded in the $\omega 3 \mathrm{D}$ rats $(6.65 \pm 0.64 \%$; $n=16)$

In the case of the other 5 long-chain polyunsaturated $\omega 6$ fatty acids (C20:2 $\omega 6, C 18: 3 \omega 3$, $\mathrm{C} 20: 4 \omega 6, \mathrm{C} 22: 4 \omega 6$ and $\mathrm{C} 22: 5 \omega 6)$, the mean value found in the $\omega 3 \mathrm{D}$ rats examined before the switch in diet always exceeded both that recorded in the 8 control animals and those 
measured in each of the three groups of $\omega 3 \mathrm{D}$ rats examined after the switch in diet. The relative magnitude of the difference between the values recorded in the $\omega 3 \mathrm{D}$ rats before the switch from the sunflower oil diet to the soya oil diet and the overall mean value found in the control animals at the end of the initial 3 months period and 8 weeks thereafter was quite variable, ranging from as little as $12.0 \pm 2.4 \%(\mathrm{df}=10 ; \mathrm{p}<0.001)$ in the case of $\mathrm{C} 20: 4 \omega 6$ to as much as a tenfold increase $(\mathrm{p}<0.001)$ in the case of $\mathrm{C} 22: 5 \omega 6$.

\begin{tabular}{|c|c|c|c|c|c|c|c|}
\hline \multicolumn{2}{|l|}{ Rats } & 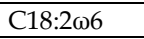 & 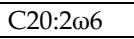 & 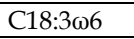 & 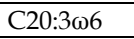 & 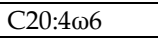 & $\mathrm{C} 22: 4 \omega 6$ \\
\hline \multicolumn{2}{|c|}{ Control before } & $82.51 \pm 5.16$ & $1.59 \pm 0.18$ & $1.72 \pm 0.25$ & $6.05 \pm 0.63$ & $303.65 \pm 5.77$ & $2.87 \pm 0.165 .27 \pm 0.48$ \\
\hline & $\operatorname{after}(8 \mathrm{wk})$ & $78.23 \pm 4.70$ & $1.57 \pm 0.12$ & $1.64 \pm 0.06$ & $8.52 \pm 1.06$ & $308.73 \pm 8.17$ & $3.99 \pm 0.139 .27 \pm 1.07$ \\
\hline \multirow[t]{4}{*}{$\omega 3 \mathrm{D}$} & before & $77.83 \pm 2.73$ & $2.78 \pm 0.80$ & $2.03 \pm 0.20$ & $5.44 \pm 0.44$ & $342.83 \pm 4.45$ & 8.54 \\
\hline & after (1wk) & $74.16 \pm 5.52$ & $1.64 \pm 0.17$ & $1.85 \pm 0.29$ & $6.73 \pm 1.51$ & $330.74 \pm 6.44$ & $5.38 \pm 0.0437 .21 \pm 5.54$ \\
\hline & $\operatorname{after}(2 \mathrm{w})$ & $77.23 \pm 2.55$ & $1.94 \pm 0.15$ & $1.61 \pm 0.13$ & $6.19 \pm 0.97$ & $330.51 \pm 2.11$ & $0.2323 .63 \pm 2.55$ \\
\hline & after (8 wk) & $76.92 \pm 6.60$ & $1.44 \pm 0.05$ & $1.74 \pm 0.19$ & $8.22 \pm 1.84$ & $324.40 \pm 3.48$ & $4.45 \pm 0.2514 .71 \pm 4.07$ \\
\hline
\end{tabular}

Table 6 . Relative weight content (\%o) of long-chain polyunsaturated $\omega 6$ fatty acids in liver phospholipids

However, when the values recorded in the $\omega 3 \mathrm{D}$ rats 1 week, 2 weeks and 8 weeks after the switch in diet, in excess of the reference value found in control animals, were expressed relative to the difference between the measurements made in the $\omega 3 \mathrm{D}$ rats before the switch in diet and the same reference value found in control animals, a time-related obliteration of the latter difference was often observed. As illustrated in Fig. 1, such a progressive decrease displayed an exponential pattern, with a half-life somewhat below one week.

\subsubsection{Saturated fatty acids}

Except in the case of C16:0 and C24:0 ( $\mathrm{p}<0.05$ or less), no significant change was observed in the control animals between the liver phospholipid relative weight content of the six saturated fatty acids listed in Table 7, as measured at the end of the 3 months initial period and 8 weeks thereafter.

\begin{tabular}{|c|c|c|c|c|c|c|}
\hline Rats & & C14:0 & C16:0 & C20:0 & $\mathrm{C} 22: 0$ & $\mathrm{C} 24: 0$ \\
\hline \multirow[t]{2}{*}{ Control } & before & $1.56 \pm 0.15$ & $133.92 \pm 2.71$ & $237.04 \pm 4.670 .70 \pm 0.01$ & $2.23 \pm 0.69$ & $6.84 \pm 0.34$ \\
\hline & after (8wk) & $1.52 \pm 0.11$ & $120.29 \pm 4.39$ & $241.12 \pm 5.760 .75 \pm 0.04$ & $3.62 \pm 0.13$ & $8.79 \pm 0.05$ \\
\hline \multirow[t]{4}{*}{$\omega 3 \mathrm{D}$} & before & $1.86 \pm 0.22$ & $144.02 \pm 5.75$ & $273.82 \pm 1.42 \quad 0.20 \pm 0.20$ & $4.42 \pm 0.20$ & $9.63 \pm 0.24$ \\
\hline & after (1 wk) & $1.74 \pm 0.14$ & $133.30 \pm 3.77$ & $261.74 \pm 7.200 .35 \pm 0.20$ & $2.78 \pm 0.93$ & $8.01 \pm 0.16$ \\
\hline & after (2 wk) & $1.81 \pm$ & $130.91 \pm 1$ & $252.75 \pm 1.550 .20 \pm 0.20$ & $3.42 \pm 0.40$ & $7.86 \pm 0.05$ \\
\hline & after (8wk) & $1.51 \pm 0.15$ & $116.45 \pm 4.95$ & $251.72 \pm 9.170 .00 \pm 0.00$ & $3.34 \pm 0.19$ & $8.42 \pm 0.56$ \\
\hline
\end{tabular}

Table 7. Relative weight content (\%o) of saturated fatty acids in liver phospholipids

The C20:0 relative weight content of liver phospholipids was lower $(p<0.001)$ in the $\omega 3 \mathrm{D}$ rats $(0.19 \pm 0.08 \%$; $\mathrm{n}=16)$ than in the control animals $(0.72 \pm 0.02 \% ; \mathrm{n}=8)$. The opposite situation prevailed for the other five saturated fatty acids (C14:0, C16:0, C18:0, C22:0 and C24:0). As documented in Fig. 2, using the same analytical procedure as that applied to the data relative to content of long-chain polyunsaturated $\omega 6$ fatty acids (Fig. 1), the switch from the sunflower oil diet to the soya oil diet provoked a time-related normalization of the liver 
phospholipid content of the just mentioned five saturated fatty acids, with a half-life close to one week. Such a progressive decrease represented a mirror image of the progressive increase in the $\mathrm{C} 22: 6 \omega 3$ relative weight content of liver phospholipids in the $\omega 3 \mathrm{D}$ rats examined after the switch in diet, with again a half-life close to one week.

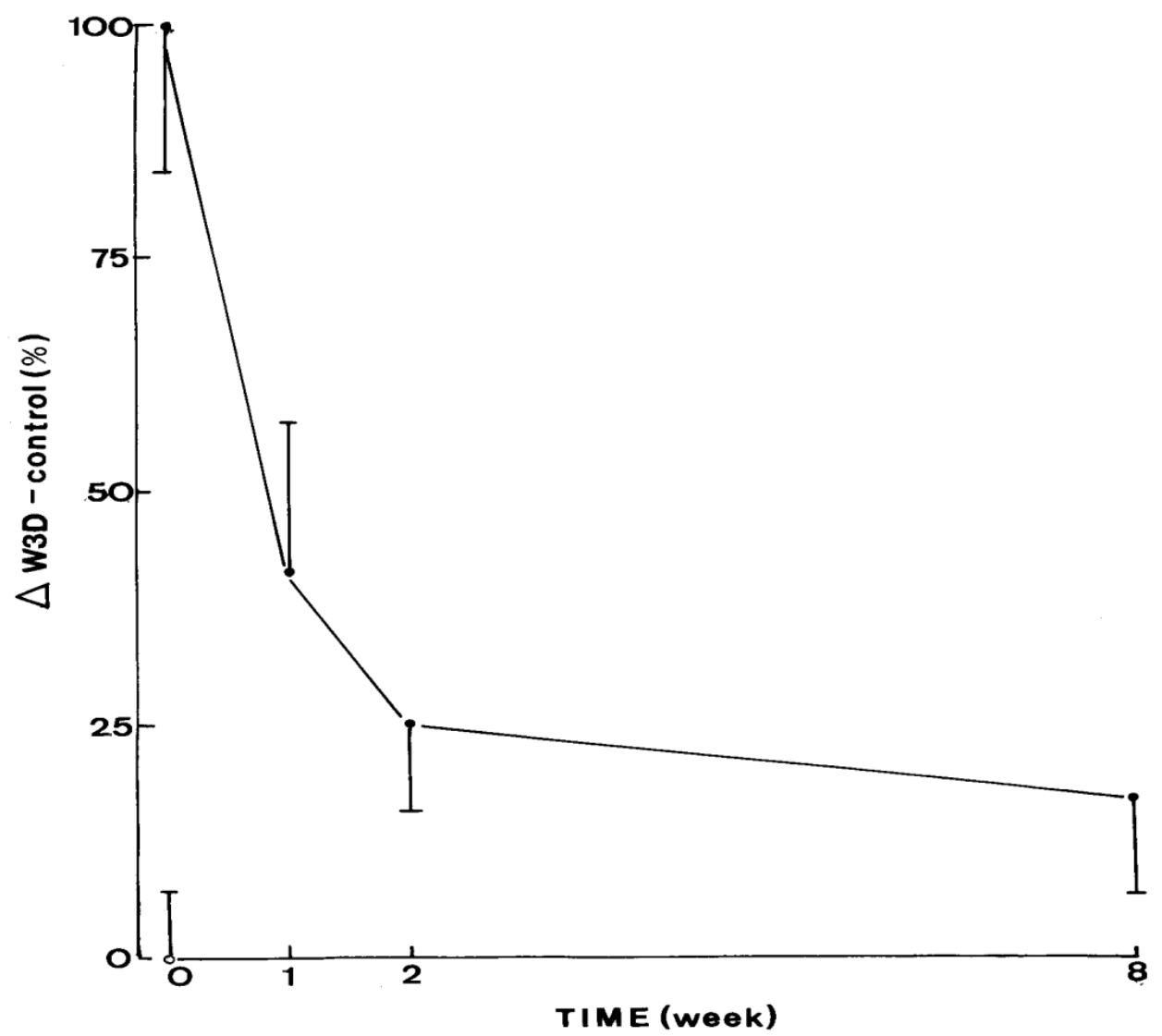

Fig. 1. Time course for the changes in the relative weight content of $C 20: 2 \omega 6, C 18: 3 \omega 6$,

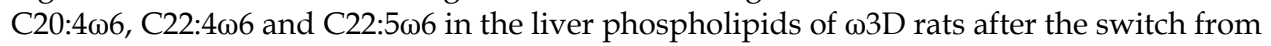
the sunflower oil to soya oil diet. For each of these five fatty acids, all individual results are expressed relative to the difference between the mean value recorded in the $\omega 3 \mathrm{D}$ rats before the switch in diet and the overall mean value found in the control animals examined at the end of the 3 months initial period and 8 weeks thereafter. Mean values ( \pm SEM) refer to 20 individual measurements in the $\omega 3 \mathrm{D}$ rats (closed circles) and 40 individual measurements in the control animals (open circle) 


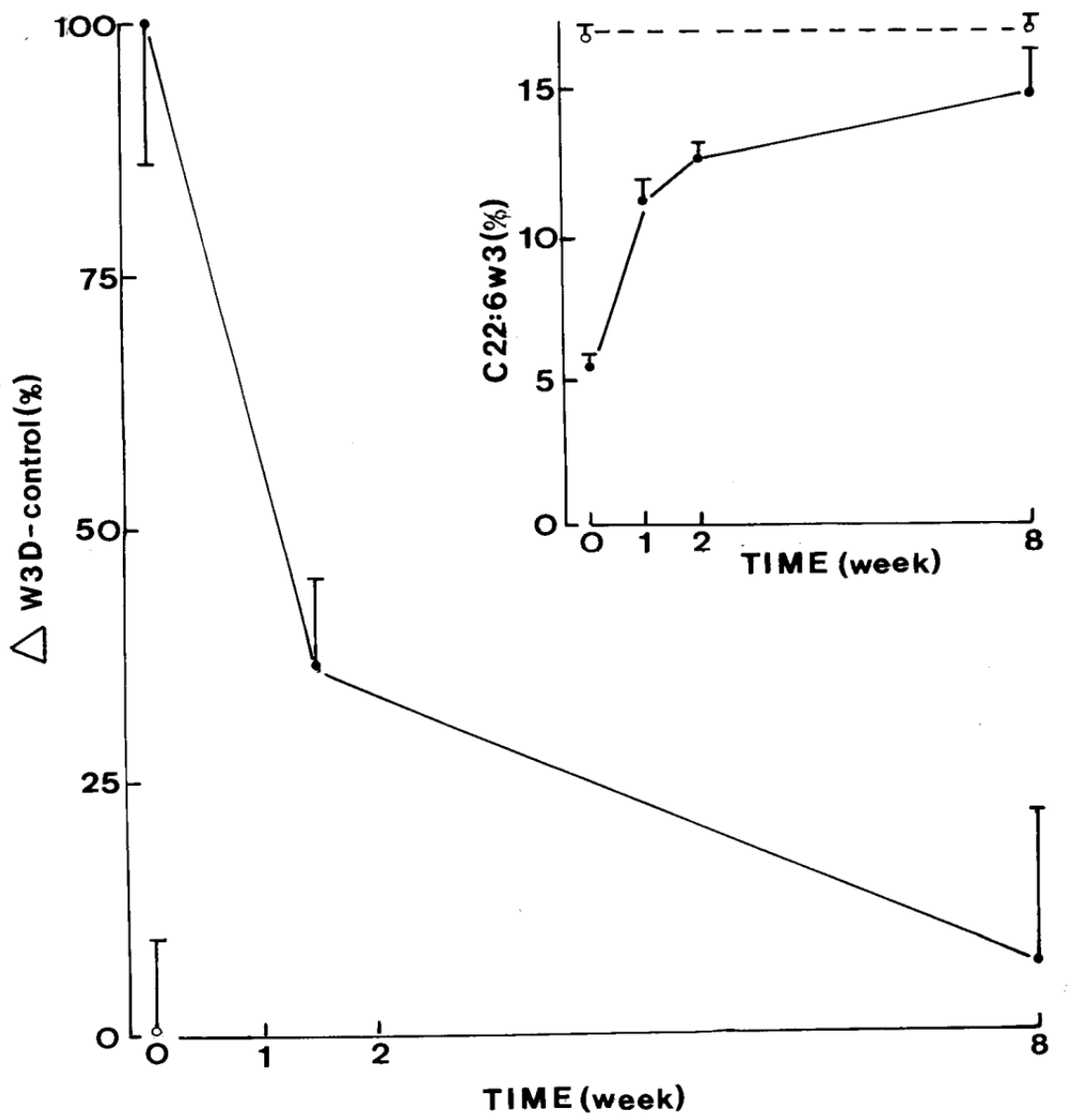

Fig. 2. Time course for the changes in the relative weight content of $\mathrm{C} 14: 0, \mathrm{C} 16: 0, \mathrm{C} 18: 0$, $\mathrm{C} 22: 0$ and $\mathrm{C} 24: 0$ in the liver phospholipids of $\omega 3 \mathrm{D}$ rats after the switch from the sunflower oil to soya oil diet. Same presentation as in Fig. 1 . The inset illustrates the time course for the changes in the relative weight content (\%) of $\mathrm{C} 22: 6 \omega 3$ in the liver phospholipids of control animals (open circles and dashed line) and $\omega 3 \mathrm{D}$ rats (closed circles and solid line); mean values $( \pm$ SEM) refer to 4 individual determinations in each case.

\subsubsection{Monodesaturated fatty acids}

No significant difference in the relative weight content of monodesaturated fatty acids

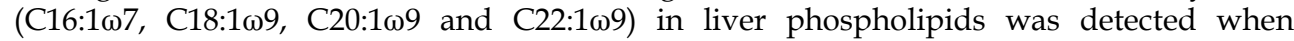
comparing control animals and $\omega 3 \mathrm{D}$ rats, whether examined at the end of the 3 months initial period or thereafter (Table 8). For instance, the C22:1 $\omega 9$ content averaged 2.08 \pm $0.20 \%$ o $(\mathrm{n}=8)$ in the control animals, and respectively $2.92 \pm 0.63 \%$ o $(\mathrm{n}=4)$ and $2.74 \pm 0.40 \%$ o $(n=12)$ in the $\omega 3 \mathrm{D}$ rats examined before and after the switch in diet. None of the latter three percentages differed significantly from one another ( $p>0.2$ or more). 


\begin{tabular}{|c|c|c|c|c|c|}
\hline Rats & & 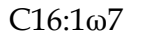 & 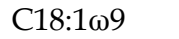 & 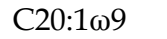 & 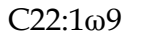 \\
\hline \multirow[t]{2}{*}{ Control } & before & $5.16 \pm 1.06$ & $23.91 \pm 2.57$ & $0.33 \pm 0.19$ & $2.04 \pm 0.24$ \\
\hline & after (1 wk) & $6.14 \pm 0.44$ & $23.04 \pm 0.80$ & $0.00 \pm 0.00$ & $2.11 \pm 0.37$ \\
\hline \multirow[t]{4}{*}{$\omega 3 \mathrm{D}$} & before & $5.83 \pm 0.96$ & $27.04 \pm 2.78$ & $0.00 \pm 0.00$ & $2.92 \pm 0.63$ \\
\hline & after (1 wk) & $5.20 \pm 1.02$ & $23.79 \pm 2.17$ & $0.16 \pm 0.16$ & $2.05 \pm 0.49$ \\
\hline & after (2 wk) & $5.57 \pm 0.74$ & $24.90 \pm 1.35$ & $0.00 \pm 0.00$ & $2.12 \pm 0.54$ \\
\hline & after (8 wk) & $5.75 \pm 0.78$ & $24.58 \pm 1.46$ & $0.00 \pm 0.00$ & $4.06 \pm 0.57$ \\
\hline
\end{tabular}

Table 8. Relative weight content (\%o) of monodesaturated fatty acids in liver phospholipids

\subsection{Fatty acid pattern of RBC phospholipids}

\subsubsection{Long-chain polyunsaturated $\omega 3$ fatty acids}

The mean values for the relative weight content of long-chain polyunsaturated $\omega 3$ fatty acids in RBC phospholipids are listed in Table 9.

In the $\omega 3 \mathrm{D}$ rats, the $\mathrm{C} 18: 3 \omega 3$ relative weight content of $\mathrm{RBC}$ phospholipids increased $(\mathrm{p}<$ $0.005)$ from a mean value of $0.62 \pm 0.36 \%$ o $(n=4)$ before the switch in diet to an overall mean value of $1.79 \pm 0.07 \%$ o $(n=6)$ thereafter. The latter mean value remained somewhat lower $(p$ $<0.06)$ than that recorded in the control animals at the end of the 3 months initial period $(2.11 \pm 0.14 \% ; n=4)$. A minor amount of $\mathrm{C} 18: 4 \omega 3(1.60 \pm 0.21 \%$; $n=4)$ was only detected in the $\omega 3 \mathrm{D}$ rats examined before the switch in diet.

\begin{tabular}{|c|c|c|c|c|c|}
\hline Rats & & 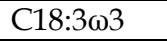 & $\mathrm{C} 20: 5 \omega 3$ & $\mathrm{C} 22: 5 \omega 3$ & 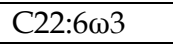 \\
\hline \multirow[t]{2}{*}{ Control } & before & $2.11 \pm 0.14$ & $4.33 \pm 0.57$ & $19.11 \pm 0.64$ & $68.11 \pm 1.39$ \\
\hline & after (8 wk) & N.T. & $3.01 \pm 0.37$ & $21.37 \pm 2.25$ & $64.84 \pm 2.84$ \\
\hline \multirow[t]{4}{*}{$\omega 3 \mathrm{D}$} & before & $0.62 \pm 0.36$ & $0.00 \pm 0.00$ & $1.82 \pm 0.14$ & $19.76 \pm 1.12$ \\
\hline & after (1 wk) & $1.88(1)$ & $1.06(1)$ & $4.53(1)$ & $27.75(1)$ \\
\hline & after (2 wk) & $1.69(1)$ & $1.36(1)$ & $5.80(1)$ & $36.31(1)$ \\
\hline & after (8 wk) & $1.79 \pm 0.10$ & $2.86 \pm 0.35$ & $14.02 \pm 1.10$ & $49.64 \pm 3.84$ \\
\hline
\end{tabular}

Table 9. Relative weight content (\%) of long-chain polyunsaturated $\omega 3$ fatty acids in RBC phospholipids

In the $\omega 3 \mathrm{D}$ rats, the $\mathrm{C} 20: 5 \omega 3$ content of RBC phospholipids also progressively increased from $0.00 \pm 0.00 \%$ o $(n=4)$ before the switch in diet to $1.21 \pm 0.15 \%$ o $(n=2)$ one to two weeks thereafter and $2.86 \pm 0.35 \%$ o $(n=4) 8$ weeks thereafter. Once again, the latter mean value remained lower $(\mathrm{p}<0.05)$ than that recorded in the control animals over the same period of 8 weeks $(4.12 \pm 0.33 \%$; $\mathrm{n}=8)$. The time-related increase in the C20:5 $\omega 3$ content of RBC phospholipids was less rapid than that found, in the same $\omega 3 \mathrm{D}$ rats, for the C20:5 $\omega 3$ content of liver phospholipids. Indeed the paired RBC/liver ratio for such contents increased in the $\omega 3 \mathrm{D}$ rats from $0.0 \pm 0.0 \%(\mathrm{n}=4)$ before the switch in diet to respectively $37.9 \%(n=1), 71.6 \%$ $(n=1)$ and $120.9 \pm 17.2 \%(n=4)$ one, two and 8 weeks thereafter. The latter mean value was no more significantly different $(\mathrm{p}>0.25)$ from the $\mathrm{RBC} /$ liver ratio found in the control animals examined either before $(98.6 \pm 19.6 \% ; n=4)$ or after $(90.6 \pm 16.7 \% ; n=4)$ the last 8 weeks of the present experiments.

A delayed alignment of the C22:5 $\omega 3$ content of RBC phospholipids on that of liver phospholipids in the $\omega 3 \mathrm{D}$ rats eventually exposed to the soya oil diet was also observed, as illustrated in Fig. 3. Thus, the liver/RBC ratio for this variable transiently increased in the 
$\omega 3 \mathrm{D}$ rats switched to the soya oil diet before resuming a mean value $(60.9 \pm 5.4 \% ; n=4)$ still somewhat higher $(\mathrm{p}<0.02)$ than that recorded in the control animals over the same period of 8 weeks $(46.2 \pm 2.5 \% ; \mathrm{n}=8)$.

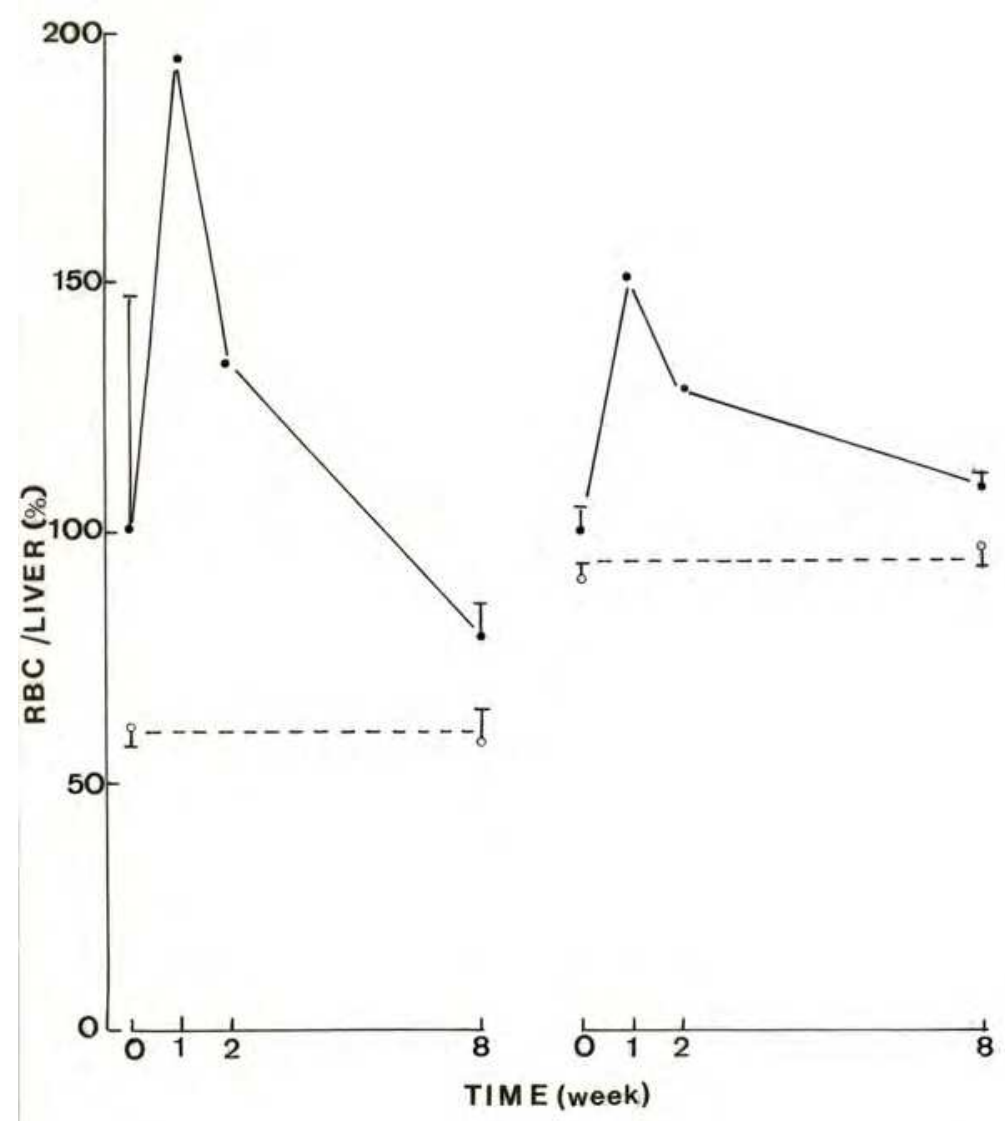

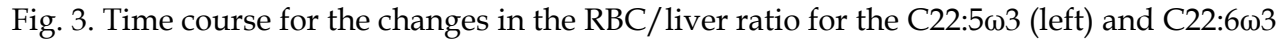
(right) relative weight content of phospholipids in control animals (open circles and dashed line) and $\omega 3 \mathrm{D}$ rats (closed circles and solid line). Single measurements made in pooled samples from 4 rats (week 1 and 2 ) or mean values $( \pm$ SEM; $n=4)$ are expressed relative to the mean value found in the $\omega 3 \mathrm{D}$ rats before the switch in diet.

Likewise, the liver/RBC ratio for the C22:6 $\omega 3$ content of phospholipids transiently increased in the $\omega 3 \mathrm{D}$ rats exposed to the soya oil diet before resuming a mean value of $300.0 \pm 6.2 \%$ (n $=4)$, still somewhat higher $(\mathrm{p}<0.003)$ than that recorded in the control animals over the same period of 8 weeks $(257.9 \pm 7.9 \% ; n=8)$. Incidentally, Fig. 3 also documents that, in the control animals, the liver/RBC ratio for either the $\mathrm{C} 22: 5 \omega 3$ or $\mathrm{C} 22: 6 \omega 3$ content of phospholipids was not significantly different ( $p>0.27$ or more) at the onset and end of the last 8 weeks period in the present experiments, as also observed ( $p>0.7)$ for the RBC/liver ratio for the $\mathrm{C} 20: 5 \omega 3$ content of phospholipids in the control animals (see above). 


\subsubsection{Long-chain polyunsaturated $\omega 6$ fatty acids}

A mirror image of that recorded for $\mathrm{C} 22: 5 \omega 3$ or $\mathrm{C} 22: 6 \omega 3$ was observed concerning the liver/ $\mathrm{RBC}$ ratio for the relative weight content of $\mathrm{C} 22: 4 \omega 6$. Thus, such a ratio, which was significantly higher $(\mathrm{p}<0.001)$ in the $\omega 3 \mathrm{D}$ rats $(33.9 \pm 1.1 \% ; \mathrm{n}=4)$ than in the control rats $(21.7 \pm 1.3 \% ; n=4)$ both examined at the end of the 3 months initial period, first decreased $(\mathrm{p}<0.025)$ in the $\omega 3 \mathrm{D}$ rats to $22.0 \pm 0.1 \%(\mathrm{n}=2)$ one to two weeks after the switch in diet and then increased again $(\mathrm{p}<0.02)$ to $27.0 \pm 1.4 \%(\mathrm{n}=4) 8$ weeks after the switch in diet, reaching a value virtually identical $(p>0.49)$ to that recorded at the same time in the control animals $(28.5 \pm 1.5 \% ; \mathrm{n}=4)$. In the case of $\mathrm{C} 22: 5 \omega 6$, the liver/RBC ratio was again significantly higher $(\mathrm{p}<0.001)$ in the $\omega 3 \mathrm{D}$ rats $(230.2 \pm 9.9 \% ; \mathrm{n}=4)$ than in the control animals $(95.5 \pm 4.4 \% ; \mathrm{n}=4)$ both examined at the end of the 3 months initial period. It decreased $(\mathrm{p}<0.005)$ in the $\omega 3 \mathrm{D}$ rats to $124.5 \pm 9.3 \%(\mathrm{n}=2)$ one to two weeks after the switch in diet, such a value being comparable to that reached 8 weeks after the switch in diet $(125.6 \pm 14.3 \% ; n=4)$ in the $\omega 3 \mathrm{D}$ rats. The latter two mean values were no more significantly different $(\mathrm{p}>0.25)$ than that recorded in the control animals at the end of the present experiments $(149.2 \pm 13.3 \% ; \mathrm{n}=4)$ and virtually identical to that prevailing in the same animals over the last 8 weeks of such experiments $(122.4 \pm 12.0 \% ; n=8)$.

\begin{tabular}{lllllllll}
\hline Rats & & $\mathrm{C} 18: 2 \omega 6$ & $\mathrm{C} 18: 3 \omega 6$ & $\mathrm{C} 20: 2 \omega 6$ & $\mathrm{C} 20: 3 \omega 6$ & $\mathrm{C} 20: 4 \omega 6$ & $\mathrm{C} 22: 4 \omega 6$ & $\mathrm{C} 22: 5 \omega 6$ \\
\hline Control before & $80.09 \pm 4.08$ & $0.17 \pm 0.17$ & $0.00 \pm 0.00$ & $4.44 \pm 0.20$ & $330.00 \pm 6.00$ & $13.35 \pm 0.79$ & $5.48 \pm 0.31$ \\
after (8 wk) & $72.40 \pm 4.76$ & $0.79 \pm 0.28$ & $0.38 \pm 0.38$ & $5.78 \pm 0.55$ & $329.36 \pm 3.91$ & $14.06 \pm 0.44$ & $6.23 \pm 0.44$ \\
$\omega 3 \mathrm{D} \quad$ before & $78.13 \pm 0.51$ & $0.22 \pm 0.22$ & $0.00 \pm 0.00$ & $3.69 \pm 0.22$ & $341.09 \pm 10.40$ & $25.21 \pm 0.43$ & $31.37 \pm 3.06$ \\
& after (1 wk) & $69.30(1)$ & $0.00(1)$ & $0.00(1)$ & $4.45(1)$ & $347.89(1)$ & $24.37(1)$ & $27.82(1)$ \\
& after (2 wk) & $78.11(1)$ & $0.00(1)$ & $1.86(1)$ & $4.23(1)$ & $350.33(1)$ & $21.10(1)$ & $20.50(1)$ \\
& after (8 wk) & $75.82 \pm 4.75$ & $0.00 \pm 0.00$ & $0.96 \pm 0.55$ & $5.42 \pm 0.48$ & $335.95 \pm 2.91$ & $16.57 \pm 0.14$ & $11.21 \pm 1.73$ \\
\hline
\end{tabular}

Table 10. Relative weight content (\%o) of long-chain polyunsaturated $\omega 6$ fatty acids in RBC phospholipids

\subsubsection{Saturated fatty acids}

Significant differences were also on occasion observed when comparing the relative weight content of selected saturated fatty acids in the RBC phospholipids of control and $\omega 3 \mathrm{D}$ rats (Table 11). For instance, the content of C18:0 averaged $178.46 \pm 2.09 \%$ o $(n=8)$ in control animals, as distinct $(\mathrm{p}<0.003)$ from $188.11 \pm 1.64 \%(\mathrm{n}=10)$ in $\omega 3 \mathrm{D}$ rats. Inversely, the C24:0 content of RBC phospholipids was higher $(\mathrm{p}<0.025)$ in the control animals $(17.05 \pm 0.87 \%$; $n=$ 8 ) than in the $\omega 3 \mathrm{D}$ rats examined before the switch in diet $(13.46 \pm 0.52 \% ; n=4)$, reascending $(p<0.001)$ to $18.50 \pm 0.68 \%(n=6)$ when the latter $\omega 3 \mathrm{D}$ rats were switched to the soya oil diet.

\begin{tabular}{lcllllll}
\hline Rats & & $\mathrm{C} 14: 0$ & $\mathrm{C} 16: 0$ & $\mathrm{C} 18: 0$ & $\mathrm{C} 20: 0$ & $\mathrm{C} 22: 0$ & $\mathrm{C} 24: 0$ \\
\hline Control & before & $1.36 \pm 0.04$ & $212.94 \pm 3.33$ & $179.33 \pm 2.25$ & $1.15 \pm 0.04$ & $6.38 \pm 0.26$ & $15.03 \pm 0.77$ \\
& after $(8 \mathrm{wk})$ & $1.51 \pm 0.07$ & $217.35 \pm 2.26$ & $177.60 \pm 3.84$ & $1.00 \pm 0.34$ & $7.50 \pm 0.32$ & $19.08 \pm 0.46$ \\
$\omega 3 \mathrm{D}$ & before & $1.50 \pm 0.06$ & $219.93 \pm 8.24$ & $189.75 \pm 3.12$ & $1.23 \pm 0.08$ & $6.52 \pm 0.33$ & $13.46 \pm 0.52$ \\
& after (1 wk) & $1.44(1)$ & $218.9(1)$ & $187.6(1)$ & $1.42(1)$ & $7.52(1)$ & $16.10(1)$ \\
& after (2 wk) & $1.44(1)$ & $205.6(1)$ & $184.9(1)$ & $1.33(1)$ & $7.77(1)$ & $17.84(1)$ \\
& after (8wk) & $1.46 \pm 0.08$ & $210.37 \pm 3.67$ & $187.4 \pm 2.93$ & $1.31 \pm 0.10$ & $8.16 \pm 0.54$ & $19.27 \pm 0.66$ \\
\hline
\end{tabular}

Table 11. Relative weight content (\%o) of saturated fatty acids in RBC phospholipids 


\subsubsection{Monodesaturated fatty acids}

The C16:1 $\omega 7$ relative weight content of RBC phospholipids averaged $2.90 \pm 0.15 \%$ o $(n=8)$ in the control animals, and $2.58 \pm 0.41 \%$ o $(n=4)$ and $2.96 \pm 0.21 \%$ o $(n=6)$ in the $\omega 3 \mathrm{D}$ rats examined, respectively, before and after the switch in diet. The corresponding values for the C18:1 $\omega 9$ content of RBC phospholipids averaged $53.08 \pm 1.46 \%$ o $(n=8), 52.91 \pm 2.47 \%$ o $(n=4)$ and $54.47 \pm 1.56 \%$ o $(n=6)$. No C20:1 199 was detected in any of the 18 samples concerned by this study. Sizeable amounts of C22:1 $\omega 9(8.14 \pm 0.20 \%$; $n=4)$ were only detected in the samples prepared from the $\omega 3 \mathrm{D}$ rats examined before the switch in diet.

\subsection{Fatty acid pattern of brain phospholipids}

\subsubsection{Long-chain polyunsaturated $\omega 3 \mathrm{D}$ fatty acids}

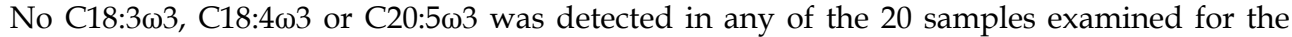
fatty acid pattern of brain phospholipids. The C22:5 $\omega 3$ and $C 22: 6 \omega 3$ relative weight content of brain phospholipids were significantly lower in $\omega 3 \mathrm{D}$ rats than in control animals both examined at the end of the 3 months initial period and, in the former $\omega 3 \mathrm{D}$ rats, slowly returned towards control values after the switch in diet (Table 12).

\begin{tabular}{|c|c|c|}
\hline Rats & $\mathrm{C} 22: 5 \omega 3$ & 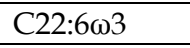 \\
\hline Control before & $2.29 \pm 0.04$ & $235.93 \pm 6.60$ \\
\hline after (8 wk) & $2.30 \pm 0.20$ & $213.34 \pm 7.43$ \\
\hline before & $0.00 \pm 0.00$ & $186.65 \pm 5.01$ \\
\hline after (1 wk) & $0.27 \pm 0.27$ & $193.19 \pm 3.72$ \\
\hline $\operatorname{after}(8 \mathrm{wk})$ & $1.95 \pm 0.14$ & $209.04 \pm 4.89$ \\
\hline
\end{tabular}

Table 12. Relative weight content (\%o) of long-chain polyunsaturated $\omega 3$ fatty acids in brain phospholipids

\subsubsection{Long-chain polyunsaturated $\omega 6$ fatty acids}

The C18:2 $\omega 6$ relative weight content of brain phospholipids was higher $(\mathrm{p}<0.02)$ in the control animals $(7.30 \pm 0.24 \% ; n=8)$ than in the $\omega 3 \mathrm{D}$ rats examined before and one week after the switch in diet $(6.27 \pm 0.29 \% ; n=8)$, resuming in the $\omega 3 \mathrm{D}$ rats exposed for 8 weeks to the soya oil diet a mean value $(7.55 \pm 0.14 \%$; $n=4)$ no more significantly different $(\mathrm{p}>$ 0.5 ) from that recorded in the control animals (Table 13). A comparable situation prevailed

\begin{tabular}{llllllll}
\hline Rats & & $\mathrm{C} 18: 2 \omega 6$ & $\mathrm{C} 20: 2 \omega 6$ & $\mathrm{C} 20: 3 \omega 6$ & $\mathrm{C} 20: 4 \omega 6$ & $\mathrm{C} 22: 4 \omega 6$ & $\mathrm{C} 22: 5 \omega 6$ \\
\hline Control & before & $7.16 \pm 0.39$ & $1.31 \pm 0.06$ & $2.48 \pm 0.09$ & $131.66 \pm 6.04$ & $26.85 \pm 1.70$ & $3.12 \pm 0.23$ \\
& after $(8 \mathrm{wk})$ & $7.45 \pm 0.31$ & $1.56 \pm 0.13$ & $2.99 \pm 0.17$ & $116.71 \pm 8.21$ & $27.23 \pm 0.93$ & $3.08 \pm 0.37$ \\
$\omega 3 \mathrm{D}$ & before & $6.27 \pm 0.58$ & $1.34 \pm 0.14$ & $2.07 \pm 0.21$ & $137.94 \pm 7.23$ & $30.21 \pm 1.63$ & $22.94 \pm 1.46$ \\
& after $(1 \mathrm{wk})$ & $6.27 \pm 0.20$ & $1.48 \pm 0.07$ & $2.30 \pm 0.19$ & $125.04 \pm 3.90$ & $28.88 \pm 1.40$ & $19.00 \pm 1.41$ \\
& after (8 wk) & $7.55 \pm 0.14$ & $1.48 / 1.58$ & $2.55 \pm 0.15$ & $122.74 \pm 3.38$ & $26.49 \pm 2.79$ & $8.30 \pm 0.54$ \\
\hline
\end{tabular}

Table 13. Relative weight content $(\%)$ of long-chain polyunsaturated $\omega 6$ fatty acids in brain phospholipids

in the case of $\mathrm{C} 20: 3 \omega 6$, with a lower value $(\mathrm{p}<0.025)$ in $\omega 3 \mathrm{D}$ rats $(2.31 \pm 0.11 \%$; $\mathrm{n}=12)$ than in control animals $(2.74 \pm 0.13 \%$; $n=18)$. Except in one control animal with a C18:3 $\omega 6$ relative content of $0.79 \%$ in brain phospholipids, no sizeable amount of this fatty acid could

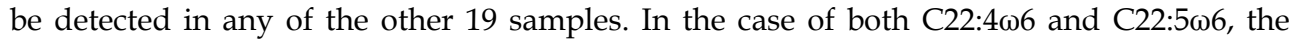
mean value recorded at the end of the initial 3 months period was higher in $\omega 3 \mathrm{D}$ rats than in 
control animals, a progressive decrease being recorded in the former $\omega 3 \mathrm{D}$ rats after the switch in diet. Such changes were most obvious in the case of C22:5 $\omega 6$.

\subsubsection{Saturated fatty acids}

As a rule, the relative weight content of saturated fatty acids in the brain phospholipids of $\omega 3 \mathrm{D}$ rats were comparable to the overall mean values found in control animals (Table 14). In the case of C14:0 and C16:0, however, the individual values collected in $\omega 3 \mathrm{D}$ rats differed significantly $(\mathrm{p}<0.004)$ from those recorded in control animals, averaging $114.0 \pm 3.1 \%$ $(\mathrm{n}=24)$ of the mean corresponding measurements made in the latter control animals $(100.0$ $\pm 2.5 \% ; \mathrm{n}=16$ ).

\begin{tabular}{|c|c|c|c|c|c|c|c|}
\hline Rats & & C14:0 & C16:0 & C18:0 & C20:0 & C22:0 & C24:0 \\
\hline \multirow[t]{2}{*}{$\overline{\text { Control }}$} & before & $1.03 \pm 0.06$ & $228.96 \pm 6.45$ & $184.97 \pm 2.01$ & $3.06 \pm 0.14$ & $2.90 \pm 0.18$ & $6.90 \pm 0.58$ \\
\hline & & $0.92 \pm 0.04$ & $194.74 \pm$ & $193.39 \pm 2.13$ & $5.31 \pm 0.91$ & $5.50 \pm 0.79$ & $12.95 \pm 1.42$ \\
\hline \multirow[t]{3}{*}{$\omega 3 \mathrm{D}$} & before & $1.11 \pm 0.07$ & $232.34 \pm 6.19$ & $188.85 \pm 2.19$ & $3.44 \pm 0.38$ & $3.54 \pm 0.80$ & $8.65 \pm 1.62$ \\
\hline & & $1.15 \pm 0.03$ & $231.48 \pm 8.04$ & $182.90 \pm 2.40$ & $4.32 \pm 0.44$ & $4.41 \pm 0.46$ & $10.13 \pm 0.98$ \\
\hline & after (8wk) & $1.21 \pm 0.13$ & $231.30 \pm 22.37$ & $186.66 \pm 6.29$ & $3.89 \pm 0.40$ & $4.09 \pm 0.76$ & $9.08 \pm 1.84$ \\
\hline
\end{tabular}

Table 14. Relative weight content (\%o) of saturated fatty acids in brain phospholipids

\subsubsection{Monodesaturated fatty acids}

In the same manner as noticed in the case of most saturated fatty acids, the relative weight content of monodesaturated fatty acids in brain phospholipids displayed in the $\omega 3 \mathrm{D}$ rats values not vastly different from the overall mean values recorded in control animals (Table 15). Thus, relative to the latter overall mean values for each monodesatuarted fatty acids found in control animals $(100.0 \pm 12.9 \% ; n=32)$, those recorded in the $\omega 3 \mathrm{D}$ rats averaged $100.0 \pm 7.1 \% ; \mathrm{n}=48)$.

\begin{tabular}{|c|c|c|c|c|}
\hline Rats & 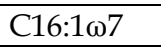 & 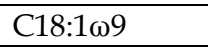 & 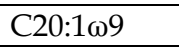 & 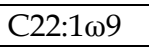 \\
\hline Control before & $3.20 \pm 0.16$ & $149.78 \pm 3.34$ & $8.39 \pm 1.01$ & $0.00 \pm 0.00$ \\
\hline after $(9 \mathrm{wk})$ & $3.36 \pm 0.13$ & $187.77 \pm 13.66$ & $16.71 \pm 2.21$ & $2.73 \pm 1.04$ \\
\hline$\omega 3 \mathrm{D}$ before & $3.05 \pm 0.24$ & $161.33 \pm 13.22$ & $9.70 \pm 2.38$ & $0.58 \pm 0.58$ \\
\hline after $(1 \mathrm{wk})$ & $3.12 \pm 0.08$ & $171.48 \pm 6.09$ & $12.37 \pm 2.34$ & $2.19 \pm 0.32$ \\
\hline after (8wk) & $3.34 \pm 0.15$ & $168.53 \pm 7.92$ & $10.40 \pm 1.32$ & $2.06 \pm 0.71$ \\
\hline
\end{tabular}

Table 15. Relative weight content (\%o) of monodesaturated fatty acids in brain phospholipids

\subsubsection{Comparison of brain, RBC and liver data}

As already observed, in the case of RBC phospholipids, the changes in the relative weight content of selected fatty acids in brain phospholipids, as recorded in the $\omega 3 \mathrm{D}$ rats after the switch from the sunflower oil diet to the soya oil diet, occurred less rapidly than those found in liver phospholipids. In such a respect, there was no significant difference $(p>0.6$ or more) when comparing the data collected in either the RBC or brain phospholipids. For instance, in the case of $\mathrm{C} 22: 5 \omega 3$ and $\mathrm{C} 22: 6 \omega 3$, the increment found in the $\omega 3 \mathrm{D}$ rats examined one week after the switch in diet, above the mean value recorded before such a switch, only represented, in brain and RBC respectively, $21.6 \pm 10.5 \%(n=8)$ and $26.0 \pm 3.8 \%(n=2)$ of the corresponding mean increment found 8 weeks after the switch in diet. The latter 
percentages yielded an overall mean value of $22.5 \pm 8.3 \%(n=10)$, significantly lower $(\mathrm{p}<$ 0.004) than that recorded under the same experimental conditions in liver, i.e. $67.5 \pm 9.3 \%$ (n

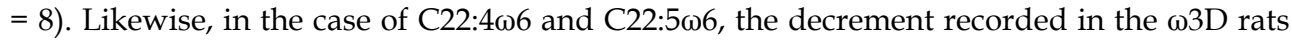
one week after the switch in diet, below the mean corresponding reference values found before such a switch, yielded in the brain and RBC, when expressed relative to the corresponding mean decrement observed 8 weeks after the switch in diet, an overall mean value of $27.8 \pm 14.4 \%(n=10)$, significantly lower $(\mathrm{p}<0.03)$ than that recorded under the same experimental conditions in liver, i.e. $69.2 \pm 5.4 \%(n=8)$. The latter two mean values relative to two long-chain polyunsaturated $\omega 6$ fatty acids were virtually identical $(p>0.75$ or more) to the corresponding mean values found in the case of the two long-chain polyunsaturated $\omega 3$ fatty acids under consideration (see above), yielding overall mean percentages of $25.1 \pm 8.1 \%(\mathrm{n}=20)$ in brain and $\mathrm{RBC}$, as compared $(\mathrm{p}<0.001)$ to $68.4 \pm 5.2 \%$ $(n=16)$ in liver.

\subsection{Fatty acid pattern in liver triglycerides}

The total fatty acid content of liver triglycerides did not differ significantly $(p>0.64)$ in the control animals and $\omega 3 \mathrm{D}$ rats, with an overall mean values of $18.3 \pm 2.5 \mathrm{mg} / \mathrm{g}$ wet wt. $(\mathrm{n}=24)$.

\subsubsection{Long-chain polyunsaturated $\omega 3$ fatty acids}

The relative weight content of $\mathrm{C} 18: 3 \omega 3, \mathrm{C} 20: 5 \omega 3, \mathrm{C} 22: 5 \omega 3$ and $\mathrm{C} 22: 6 \omega 3$ in liver triglycerides was significantly lower ( $p<0.02$ or less) in the $\omega 3 \mathrm{D}$ rats than in the control animals, both examined at the end of the 3 months initial period (Table 16). In the control animals, no significant difference was observed between the former results and those recorded 8 weeks later. In the $\omega 3 \mathrm{D}$ rats examined after the switch in diet, C20:5 $\omega 3$ remained below the limit of detection in all, except one, rats. The C18:3 $\omega 3, \mathrm{C} 22: 5 \omega 3$ and $\mathrm{C} 22: 6 \omega 3$ contents increased, however, in the $\omega 3 \mathrm{D}$ rats within one week after the switch in diet, remaining then at a plateau level somewhat lower than the mean value otherwise found in control rats. Thus, relative to such a reference value $(100.0 \pm 7.9 \% ; n=24)$, the measurements made in the $\omega 3 \mathrm{D}$ rats examined after the switch in diet averaged $66.1 \pm 5.3 \%(n=36 ; p<0.001)$.

\begin{tabular}{|c|c|c|c|c|}
\hline Rats & $\mathrm{C} 18: 3 \omega 3$ & C20:5 $\omega 3$ & $\mathrm{C} 22: 5 \omega 3$ & 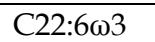 \\
\hline Control before & $12.82 \pm 2.96$ & $2.01 \pm 0.27$ & $3.41 \pm 0.56$ & $7.04 \pm 1.08$ \\
\hline after $(8 w k)$ & $11.94 \pm 3.03$ & $1.61 \pm 0.51$ & $3.06 \pm 0.90$ & $6.45 \pm 1.20$ \\
\hline before & $1.81 \pm 0.69$ & $0.00 \pm 0.00$ & $0.00 \pm 0.00$ & $0.48 \pm 0.48$ \\
\hline after (1 wk) & $8.86 \pm 2.26$ & $0.00 \pm 0.00$ & $1.81 \pm 0.83$ & $3.66 \pm 1.48$ \\
\hline after (2 wk) & $10.23 \pm 0.56$ & $0.00 \pm 0.00$ & $2.07 \pm 0.19$ & $4.55 \pm 0.47$ \\
\hline after (8wk) & $8.84 \pm 1.99$ & $0.12 \pm 0.12$ & $1.81 \pm 0.55$ & $4.80 \pm 1.70$ \\
\hline
\end{tabular}

Table 16. Relative weight content $(\%)$ in long-chain polyunsaturated $\omega 3$ fatty acids in liver triglycerides

\subsubsection{Long-chain polyunsaturated $\omega 6$ fatty acids}

The C18: $2 \omega 6$ relative weight content of liver triglycerides was virtually identical in control animals and $\omega 3 \mathrm{D}$ rats, whether at the onset or end of the last 8 weeks period of the present experiments (Table 17). Likewise, no significant difference was found between the mean values found in the six groups of rats when considering the relative weight content of $\mathrm{C} 18: 3 \omega 6$,

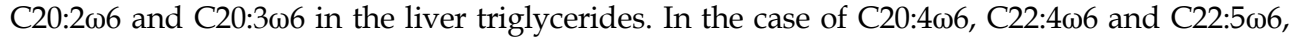


no significant difference ( $\mathrm{p}>0.3$ or more) was observed between the control animals examined

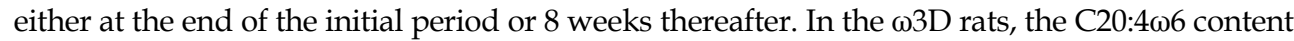
progressively decreased as a function of the length of exposure to the soya oil diet $(r=-0.5059$; $n=16 ; p<0.05)$, eventually reaching a mean value comparable $(p>0.9)$ to that recorded at the same time in the control animals. A comparable situation prevailed in the case of C22:4 46 and

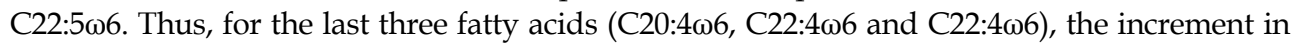
the relative weight content found in $\omega 3 \mathrm{D}$ rats above the mean corresponding value $(n=8$ in each case) recorded in the control animals, when expressed relative to the initial increment found before the switch in diet, decreased $(\mathrm{p}<0.02)$ from $100.0 \pm 17.5 \%(\mathrm{n}=12)$ to $49.6 \pm 11.3 \%$ $(n=24)$ one to two weeks after the switch in diet and further decreased $(p<0.025)$ to $3.6 \pm$ $15.6 \%(n=12)$ eight weeks after the switch in diet.

\begin{tabular}{|c|c|c|c|c|c|c|c|c|}
\hline \multirow{2}{*}{$\frac{\text { Rats }}{\text { Control }}$} & & 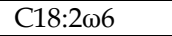 & 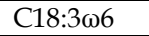 & $\mathrm{C} 20: 2 \omega 6$ & 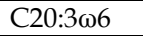 & 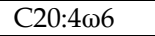 & 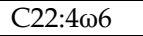 & 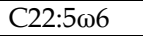 \\
\hline & before & $235.21 \pm 34.5$ & $5.35 \pm 0.38$ & $1.78 \pm 0.09$ & $1.65 \pm 0.22$ & $20.14 \pm 2.57$ & $2.61 \pm 0.63$ & $0.73 \pm 0.45$ \\
\hline & & & & $1.80 \pm$ & 1.78 & 15.22 & 2.92 & $72 \pm 0.27$ \\
\hline \multirow[t]{4}{*}{$\omega 3 \mathrm{D}$} & bef & $237.23 \pm 4$ & $5.17 \pm 0.88$ & $1.75 \pm 0.65$ & $1.92 \pm 0.83$ & $33.92 \pm 6.30$ & $6.15 \pm 1.30$ & $4.62 \pm 0.78$ \\
\hline & & $194.60 \pm$ & $01 \pm$ & $1.94 \pm 0$ & $1.65 \pm 0.22$ & $23.07 \pm 6.69$ & $4.49 \pm 1.47$ & $3.17 \pm 1.08$ \\
\hline & & $8.50 \pm 3$ & $4.73 \pm 0$ & $1.73 \pm 0$. & $2.24 \pm 0.50$ & $24.75 \pm 3.55$ & $4.93 \pm 0.86$ & $2.42 \pm 0.55$ \\
\hline & afte & $173.01 \pm 45$ & $4.25 \pm 0.66$ & $1.76 \pm 0.27$ & $1.79 \pm 0.63$ & $16.08 \pm 5.93$ & $3.29 \pm 1.08$ & $0.93 \pm 0.55$ \\
\hline
\end{tabular}

Tale 17. Relative weight content (\%o) of long-chain polyunsaturated $\omega 6$ fatty acids in liver triglycerides

\subsubsection{Saturated fatty acids}

The C12:0 relative weight content of liver triglycerides averaged $0.72 \pm 0.16 \%$ o $(n=8)$ and $0.35 \pm 0.12 \%$ o $(\mathrm{n}=16)$ in the control animals and $\omega 3 \mathrm{D}$ rats, respectively, these two mean values failing to differ significantly $(p<0.09)$ from one another. Likewise, the C14:0, C16:0 and C18:0 contents of liver triglycerides were essentially comparable in the six groups of rats considered in Table 18. A significant amount of C20:0 $(0.37 \pm 0.14 \%$; $n=8 ; \mathrm{p}<0.05)$ was detected in the control animals, whilst such was not the case $(0.02 \pm 0.02 \%$; $n=16 ; \mathrm{p}>0.3)$ in the $\omega 3 \mathrm{D}$ rats. Inversely, a significant amount of $\mathrm{C} 22: 0(0.52 \pm 0.17 \% ; \mathrm{n}=12 ; \mathrm{p}<0.02)$ was detected in the $\omega 3 \mathrm{D}$ rats examined before the switch in diet and one to two weeks thereafter, whilst such was no more the case 8 weeks after the switch in diet, null values being also recorded in the 8 control animals. No C24:0 was detected in any of the 24 samples examined in this study.

\begin{tabular}{|c|c|c|c|c|c|c|c|c|}
\hline Rats & & C12:0 & C14:0 & C16:0 & C18:0 & C20:0 & C22:0 & C24:0 \\
\hline \multicolumn{2}{|c|}{ Control before } & $0.77 \pm 0.26$ & $11.54 \pm 1.47$ & $291.91 \pm 14.36$ & $21.83 \pm 2.40$ & $0.41 \pm 0.23$ & $0.00 \pm 0.00$ & $0.00 \pm 0.00$ \\
\hline & after (8wk) & $0.70 \pm 0.24$ & $14.22 \pm 2.13$ & $345.81 \pm 27.78$ & $25.09 \pm 3.20$ & $0.33 \pm$ & $0.00 \pm 0.00$ & 0.00 \\
\hline \multirow[t]{4}{*}{$\omega 3 \mathrm{D}$} & before & $0.21 \pm$ & $11.92 \pm 1.75$ & 307.56 & $29.56 \pm 3.48$ & $0.00 \pm$ & $0.66 \pm$ & 0.00 \\
\hline & & 24 & $13.54 \pm 1.17$ & $349.41 \pm$ & $27.83 \pm 2.86$ & $0.00=$ & $0.34 \pm 0.07$ & 0.00 \\
\hline & & 0 & $13.54 \pm 1.59$ & $304.80 \pm 16$ & $24.35 \pm 1.64$ & $0.00 \pm 0.00$ & $0.56 \pm 0.41$ & $0.00 \pm 0.00$ \\
\hline & after (8wk) & $0.45 \pm 0.27$ & $15.13 \pm 1.74$ & $344.48 \pm 35.98$ & $28.62 \pm 2.99$ & $0.08 \pm 0.08$ & $0.00 \pm 0.00$ & $0.00 \pm 0.00$ \\
\hline
\end{tabular}

Table 18. Relative weight content (\%o) of saturated fatty acids in liver triglycerides

\subsubsection{Monodesaturated fatty acids}

No significant difference in the relative weight content of either C16:1 $\omega 7$ or C18:1 $\omega 9$ in liver triglycerides was observed between the six groups of rats listed in Table 19. Except in one 


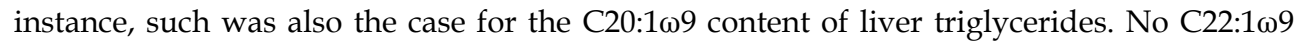
was detected in any of the 24 samples under consideration. The sole statistically significant finding consisted in the positive correlation $(\mathrm{r}=+0.9958 ; \mathrm{n}=4 ; \mathrm{p}<0.01)$ prevailing between the mean values for the $\mathrm{C} 16: 1 \omega 7$ and $\mathrm{C} 18: 1 \omega 9$ relative content recorded in the $\omega 3 \mathrm{D}$ rats (all expressed relative to the mean corresponding value found in the eight control animals) and the length of exposure to the soya oil diet (semi-logarithmic analysis). Indeed, relative to such a reference value $(100.0 \pm 4.9 \% ; \mathrm{n}=16)$, the measurements made in the $\omega 3 \mathrm{D}$ rats averaged $85.7 \pm 6.9 \%(n=8)$ before the switch in diet and $91.9 \pm 5.7 \%(n=8), 93.9 \pm 6.6 \%(n=$ $8)$ and $101.5 \pm 6.7 \%(n=8)$, respectively, one, two and eight weeks thereafter.

\begin{tabular}{|c|c|c|c|c|}
\hline Rats & $\mathrm{C} 16: 1 \omega 7$ & 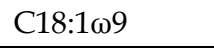 & 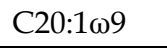 & 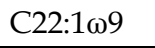 \\
\hline Control before & $54.15 \pm 9.90$ & $325.12 \pm 16.65$ & $1.30 \pm 0.13$ & $0.00 \pm 0.00$ \\
\hline after (8 wk) & $65.55 \pm 5.93$ & $322.72 \pm 13.35$ & $1.28 \pm 0.15$ & $0.00 \pm 0.00$ \\
\hline before & $45.40 \pm 6.55$ & $309.22 \pm 20.00$ & $1.27 \pm 0.49$ & $0.00 \pm 0.00$ \\
\hline after (1 wk) & $53.92 \pm 6.96$ & $303.93 \pm 11.47$ & $1.37 \pm 0.49$ & $0.00 \pm 0.00$ \\
\hline after (2 wk) & $51.78 \pm 7.12$ & $327.78 \pm 16.36$ & $1.42 \pm 0.49$ & $0.00 \pm 0.00$ \\
\hline after (8 wk) & $59.68 \pm 8.20$ & $334.84 \pm 14.10$ & $0.41 \pm 0.25$ & $0.00 \pm 0.00$ \\
\hline
\end{tabular}

Table 19. Relative weight content (\%o) of monodesaturated fatty acids in liver triglycerides

\subsection{Fatty acid profile of visceral adipose tissue lipids}

As indicated in Table 20, no significant difference was observed between control animals and $\omega 3 \mathrm{D}$ rats in terms of body weight and visceral or parametrial adipose tissue weight, whether at the end of the 3 months initial period or 8 weeks thereafter.

\begin{tabular}{|c|c|c|c|c|}
\hline & Body wt (g) & Visceral adipose tissue $(\mathrm{g})$ & Parametrial adipose tissue $(\mathrm{g})$ \\
\hline \multirow{2}{*}{ Control } & before & $360.5 \pm 17.6$ & $9.5 \pm 1.4$ & $16.0 \pm 3.4$ \\
\hline & after (8 wk) & $463.0 \pm 18.8$ & $16.5 \pm 2.1$ & $23.0 \pm 3.2$ \\
\hline \multirow[t]{2}{*}{$\omega 3 \mathrm{D}$} & before & $380.5 \pm 21.8$ & $13.5 \pm 1.6$ & $14.1 \pm 4.0$ \\
\hline & after $(8 \mathrm{wk})$ & $445.8 \pm 49.1$ & $12.3 \pm 1.8$ & $19.1 \pm 1.1$ \\
\hline
\end{tabular}

Table 20. Body weight and visceral or parametrial adipose tissue weight

The total fatty acid content of visceral adipose tissue lipids was not significantly different ( $\mathrm{p}$ $>0.5)$ in control animals $(1.19 \pm 0.03 \mathrm{mg} / \mathrm{mg}$ wet wt.; $\mathrm{n}=8)$ and $\omega 3 \mathrm{D}$ rats $(1.21 \pm 0.03$ $\mathrm{mg} / \mathrm{mg}$ wet wt.; $\mathrm{n}=8$ ).

\subsubsection{Long-chain polyunsaturated $\omega 3$ fatty acids}

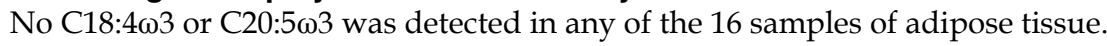

The C18:3 33 relative weight content averaged $20.36 \pm 0.83$ and $18.39 \pm 0.62 \%$ o $(n=4$ in both cases) in the control animals examined at the end of the 3 months initial period and 8 weeks thereafter. In the $\omega 3 \mathrm{D}$ rats, it increased ( $\mathrm{p}<0.001)$ from $0.00 \pm 0.00$ to $11.67 \pm 0.92 \%$ o $(\mathrm{n}=4$ in both cases) before and 8 weeks after the switch in diet. It thus remained lower $(p<0.001)$ in the $\omega 3 \mathrm{D}$ rats than in the control animals even at the end of the experiments.

The C22:5 $\omega 3$ content of adipose tissue was comparable at the end of the 3 months initial period and 8 weeks thereafter, with overall mean values of $1.21 \pm 0.11 \%$ o $(n=8)$ in control 
animals and $0.00 \pm 0.00 \%$ o $(n=8)$ in $\omega 3 \mathrm{D}$ rats. Likewise, no $\mathrm{C} 22: 6 \omega 3$ was detected in any of the eight $\omega 3 \mathrm{D}$ rats, as distinct $(\mathrm{p}<0.05)$ from an overall mean value of $1.14 \pm 0.44 \%$ in the eight control animals (Table 21).

\begin{tabular}{lllll}
\hline Rats & $\mathrm{C} 18: 3 \omega 3$ & $\mathrm{C} 20: 5 \omega 3$ & $\mathrm{C} 22: 5 \omega 3$ & $\mathrm{C} 22: 6 \omega 3$ \\
\hline Control before & $20.36 \pm 0.83$ & $0.00 \pm 0.00$ & $1.11 \pm 0.19$ & $0.00 \pm 0.00$ \\
$\quad$ after $(8 \mathrm{wk})$ & $18.39 \pm 0.62$ & $0.00 \pm 0.00$ & $1.32 \pm 0.12$ & $2.29 \pm 0.21$ \\
$\omega 3 \mathrm{D} \quad$ before & $0.00 \pm 0.00$ & $0.00 \pm 0.00$ & $0.00 \pm 0.00$ & $0.00 \pm 0.00$ \\
$\quad$ after $(8 \mathrm{wk})$ & $11.67 \pm 0.92$ & $0.00 \pm 0.00$ & $0.00 \pm 0.00$ & $0.00 \pm 0.00$ \\
\hline
\end{tabular}

Table 21. Relative weight content (\%o) of long-chain polyunsaturated $\omega 3$ fatty acids in visceral adipose tissue lipids

\subsubsection{Long-chain polyunsaturated $\omega 6$ fatty acids}

The C18:2 $\omega 6$ relative weight content of adipose tissue lipids was comparable ( $p>0.45$ or more) in control animals and $\omega 3 \mathrm{D}$ rats, whether at the onset or end of the last 8 weeks period (Table 22).

\begin{tabular}{|c|c|c|c|c|c|c|c|}
\hline \multirow{3}{*}{$\frac{\text { Rats }}{\text { Control }}$} & & 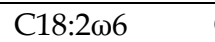 & 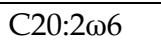 & 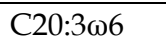 & 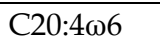 & 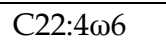 & 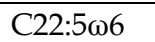 \\
\hline & befor & $303.06 \pm 13.00$ & $2.52 \pm 0.06$ & $0.00 \pm 0.00$ & $6.72 \pm 1.13$ & $1.28 \pm 0.29$ & $0.00 \pm 0.00$ \\
\hline & after (8 wk) & $276.14 \pm$ & $2.57 \pm$ & 0.36 & 6.52 & 1.50 & $0.14 \pm 0.14$ \\
\hline$\omega 3 \mathrm{D}$ & before & $324.61 \pm$ & $2.67 \pm 0.10$ & $0.00 \pm 0.00$ & $8.21 \pm 0.93$ & $2.09 \pm 0$ & $1.45 \pm 0.21$ \\
\hline
\end{tabular}

Table 22. Relative weight content (\%o) of long-chain polyunsaturated $\omega 6$ fatty acids in visceral adipose tissue lipids

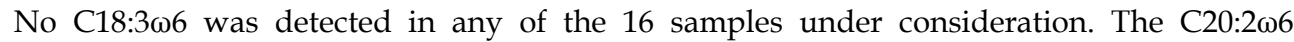
content was comparable in the 4 groups of rats. A sizeable amount of C20:3 $\omega 6$ (1.46 $\pm 0.00 ; n$ $=2$ ) was only detected in two out of 16 samples. The C20:4 $\omega 6$ content was not significantly higher $(p>0.1)$ in the $\omega 3 \mathrm{D}$ rats examined before the switch in diet $(8.21 \pm 0.93 \% ; n=4)$ than in the other rats $(6.73 \pm 0.39 \% ; n=12)$. The $C 22: 4 \omega 6$ content was significantly higher $(\mathrm{p}<$ $0.02)$, however, in the $\omega 3 \mathrm{D}$ rats examined before the switch in $\operatorname{diet}(2.09 \pm 0.25 \% ; n=4)$ than in the other animals $(1.45 \pm 0.11 \%$; $n=12)$. Likewise, the C22:5 $\omega 6$ content found in the $\omega 3 \mathrm{D}$ rats examined before the switch in diet $(1.45 \pm 0.21 \%$; $\mathrm{n}=4)$ exceeded $(\mathrm{p}<0.05$ or less) that found in either the control animals $(0.07 \pm 0.07 \%$; $n=8)$ or the $\omega 3 \mathrm{D}$ rats examined 8 weeks after the switch in diet $(0.63 \pm 0.25 \%$; $\mathrm{n}=4)$.

\subsubsection{Saturated fatty acids}

The relative weight content of C12:0, C14:0, C16:0 and C18:0 were comparable to one another in the four groups of rats (Table 23). The sole significant difference $(p<0.02)$

\begin{tabular}{llllll}
\hline Rats & C12:0 & C14:0 & C16:0 & C18:0 \\
\hline Control & before & $0.72 \pm 0.09$ & $9.57 \pm 0.93$ & $253.51 \pm 5.71$ & $30.07 \pm 1.20$ \\
& after $(8 \mathrm{wk})$ & $0.68 \pm 0.04$ & $9.52 \pm 0.59$ & $264.89 \pm 2.80$ & $30.26 \pm 0.76$ \\
$\omega 3 \mathrm{D}$ & before & $0.77 \pm 0.07$ & $10.57 \pm 1.13$ & $253.17 \pm 11.65$ & $34.09 \pm 1.78$ \\
& after $(8 \mathrm{wk})$ & $0.74 \pm 0.05$ & $10.48 \pm 0.59$ & $261.90 \pm 7.80$ & $29.79 \pm 1.61$ \\
\hline
\end{tabular}

Table 23. Relative weight content (\%o) of saturated fatty acids in visceral adipose tissue lipids 
concerned the comparison between the C18:0 content of the $\omega 3 \mathrm{D}$ rats examined before the switch in diet $(34.1 \pm 1.8 \% ; \mathrm{n}=4)$ and the other animals $(30.0 \pm 0.7 \%$; $\mathrm{n}=12)$.

No C20:0 or C24:0 was detected in any of the 16 samples of adipose tissue. A sizeable amount of $\mathrm{C} 22: 0(0.55 \pm 0.04 \% ; n=2)$ was only found in two out of four $\omega 3 \mathrm{D}$ rats examined before the switch in diet.

\subsubsection{Monodesaturated fatty acids}

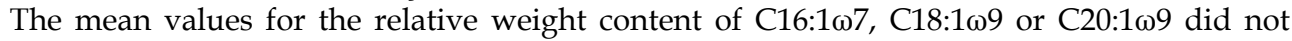
differ significantly from one another in the four groups of rats under consideration (Table 24). No C22:1 19 could be detected in any of the 16 samples of visceral adipose tissue.

\begin{tabular}{|c|c|c|c|c|}
\hline Rats & & $\mathrm{C} 16: 1 \omega 7$ & 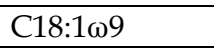 & 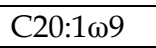 \\
\hline \multirow[t]{2}{*}{ Control } & before & $39.95 \pm 3.73$ & $328.06 \pm 7.87$ & $1.83 \pm 0.10$ \\
\hline & after (8 wk) & $40.90 \pm 3.13$ & $341.94 \pm 3.67$ & $1.77 \pm 0.05$ \\
\hline \multirow[t]{2}{*}{$\omega 3 \mathrm{D}$} & before & $38.02 \pm 7.35$ & $321.17 \pm 9.80$ & $1.75 \pm 0.16$ \\
\hline & after (8 wk) & $40.07 \pm 3.25$ & $342.42 \pm 13.01$ & $1.68 \pm 0.03$ \\
\hline
\end{tabular}

Table 24. Relative weight content (\%o) of monodesaturated fatty acids in visceral adipose tissue lipids

\subsection{Food intake and body weight}

As indicated in Table 25, over the last 7-8 weeks of the present experiments, both the food intake and relative gain in body weight were higher ( $p<0.05$ or less) in the $\omega 3 \mathrm{D}$ rats maintained on the sunflower oil diet than in either the control rats maintained on the soya oil diet or the $\omega 3 \mathrm{D}$ rats switched to the latter diet. It could be objected that the relative magnitude of the changes in body weight exceeded that of the changes in food intake. However, taking into account the differences in both body weight gain and food intake, the estimated caloric efficiency was close to the expected theoretical value, as documented by the following considerations. In one group of $4 \omega 3 \mathrm{D}$ rats maintained for a further period of 7 weeks on the sunflower diet, the daily food intake $(19.61 \pm 0.27 \mathrm{~g} /$ day per rat; $\mathrm{n}=30)$ exceeded by $1.93 \pm 0.51 \mathrm{~g} /$ day per rat $(\mathrm{p}<0.001)$ that recorded in one group of 4 control animals maintained on the soya oil diet $(17.68 \pm 0.43 \mathrm{~g} /$ day per rat; $\mathrm{n}=30)$. In these two groups of rats, the gain in body weight over the same period of 7 weeks averaged $1.93 \pm 0.14$ $\mathrm{g} /$ day per rat in the $\omega 3 \mathrm{D}$ rats as distinct $(\mathrm{p}<0.02)$ from $1.09 \pm 0.11 \mathrm{~g} /$ day per rat in the control animals. The caloric requirement to account for the difference in body weight gain $(\leq$ $7.6 \pm 1.6 \mathrm{cal})$ was thus commensurate with the increase in the caloric supply of the diet $(6.2 \pm$ $1.6 \mathrm{cal})$, which provided about $3.2 \mathrm{cal} / \mathrm{g}$.

\begin{tabular}{llll}
\hline Rats & Food intake & Relative gain in body weight ${ }^{\mathrm{b}}$ \\
\hline Control & soya oil diet & $100.0 \pm 1.6(31)$ & $13.35 \pm 1.38(4)$ \\
$\omega 3 \mathrm{D}$ & sunflower oil diet & $112.1 \pm 2.5(56)$ & $24.67 \pm 1.82(2)$ \\
$\omega 3 \mathrm{D}$ & soya oil diet & $104.4 \pm 1.6(45)$ & $12.97 \pm 2.70(4)$ \\
\hline
\end{tabular}

aThe food intake over the last 8 weeks of the present experiments is expressed relative to the mean value found at the same time after the initial 3 months period in control animals maintained on the soya oil diet bThe relative gain in body weight (\%) was assessed by comparison of individual measurements made at the end of the initial 3 months period and seven weeks thereafter

Table 25. Food intake and relative gain in body weight 


\subsection{HOMA index for insulin resistance}

At the end of the 3 months initial period, the logarithmic values of the HOMA index for insulin resistance were higher $(\mathrm{df}=4 ; \mathrm{p}<0.02)$ in the $\omega 3 \mathrm{D}$ rats than in the control animals. In the former $\omega 3 \mathrm{D}$ rats, such values progressively decreased after the switch in diet as a function of the length of exposure to the soya oil diet $(r=-0.5956 ; n=12 ; p<0.05)$. Eight weeks after the switch in diet, the HOMA index eventually reached in the $\omega 3 \mathrm{D}$ rats a mean value $(1.16 \pm 0.09 \mathrm{U} / 1 . \mathrm{mM} ; \mathrm{n}=3)$ comparable $(\mathrm{p}>0.7)$ to that found at the same time in the control animals also exposed to the soya oil diet $(1.20 \pm 0.05 \mathrm{U} / 1 . \mathrm{mM} ; \mathrm{n}=3)$.

\section{Discussion}

The present experimental design prevents any undesirable aggravation of liver steatosis and visceral obesity, as well as food intake, otherwise resulting from an increase in the lipid content of the diet from 5 to 10\% (Malaisse et al., 2009; Sener et al., 2009). It also caused correction of insulin resistance in the $\omega 3 \mathrm{D}$ rats.

The exposure of $\omega 3 \mathrm{D}$ to the soya oil diet also allowed the repletion of long-chain polyunsaturated $\omega 3$ fatty acids in the intestinal tract, liver, red blood cell and brain phospholipids.

The changes in the fatty acid pattern of tissue lipids were not always merely and directly attributable to the respective content of each diet in a given fatty acid, as documented by the accumulation of selected long-chain polyunsaturated $\omega 6$ fatty acids in the phospholipids of $\omega 3 \mathrm{D}$ rats and the correction of this situation after the switch from the sunflower oil to soya oil diet. Incidentally, before such a switch the total amount of four $\omega 3$ fatty acids (C18:3 $\omega 3$,

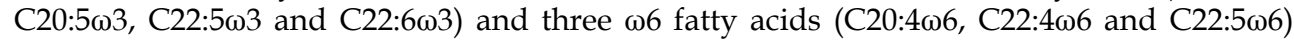
was comparable in the control animals and $\omega 3 \mathrm{D}$ rats (Carpentier et al., 2011b).

The present findings also support the view that a transfer of information takes place between the liver and either RBC or brain, as documented for instance by the delayed alignment of the phospholipid fatty acid pattern in the latter two sites on that prevailing at the hepatic level. It was recently proposed that such a process may even be operative in the absence of any dietary deprivation of long-chain polyunsaturated $\omega 3$ fatty acids (Malaisse et al., 2010).

Last, the present findings provide further evidence to the fact that changes in the dietary supply of $\omega 3$ fatty acids may also affect the relative content of tissue lipids in selected saturated and monodesaturated fatty acids.

In conclusion, the procedure used in the present experiments appears indeed suitable to ensure the repletion of long-chain polyunsaturated $\omega 3$ fatty acids in previously $\omega 3$-depleted rats.

\section{Acknowledgment}

We are grateful to C. Demesmaeker for secretarial help.

\section{References}

Carpentier, Y.A.; Hacquebard, M., Portois, L., Dupont, I.E., Deckelbaum, R.J. \& Malaisse, W.J. (2010). Rapid cellular enrichment of eicosapentaenoate after a single intravenous injection of a novel medium-chain triacylglycerol:fish oil emulsion in humans. American Journal of Clinical Nutrition, Vol. 91, 875-882. 
Malaisse, W.J. ; Hacquebard, M., Zhang, Y., Bulur, N., Sener, A. \& Carpentier, Y.A. (2011). The metabolic syndrome of $\omega 3$-depleted rats. X. Comprehensive view. The Open Physiology Journal, Vol. 4, 1-10.

Hacquebard, M. ; Portois, L., Malaisse, W.J. \& Carpentier, Y.A. (2009). The metabolic syndrome of $\omega 3$-depleted rats. IV. Intestinal phospholipid $\omega 3$ fatty acids. International Journal of Molecular Medicine, Vol. 24, 859-865.

Malaisse, W.J. ; Bulur, N., Zhang, Y., Hacquebard, M., Portois, L., Sener, A. \& Carpentier, Y.A. (2009). The metabolic syndrome of $\omega 3$-depleted rats. I. Liver data. International Journal of Molecular Medicine, Vol. 24, 111-123.

Carpentier, Y.A.; Zhang, J., Hacquebard, M. \& Malaisse, W.J. (2011a).The metabolic syndrome of $\omega 3$-depleted rats: dietary changes in lipid fatty acid pattern without changes in total lipid content. V. Red blood cell phospholipids. Metabolic and Functional Research on Diabetes, Vol. 4 (suppl. 1), in press.

Portois, L.; Hacquebard, M., Malaisse, W.J. \& Carpentier, Y.A. (2009). The metabolic syndrome of $\omega 3$-depleted rats. III. Brain phospholipids. International Journal of Molecular Medicine, Vol. 24, 269-278.

Portois, L. ; Delporte, C., Malaisse, W.J. \& Carpentier, Y.A. (2007). Fatty acid pattern of epiploic and parametrial lipids in second generation rats depleted in long-chain polyunsaturated $\omega 3$ fatty acids. Trends in Cell \& Molecular Biology, Vol. 2, 55-68.

Folch, J. ; Lees, M. \& Sloane-Stanley, G.H. (1957). A simple method for the isolation and purification of total lipids from animal tissues. Journal of Biological Chemistry, Vol. 226, 497-509.

Dahlan, W.; Richelle, M., Kulapongse, S., Rössle, C., Deckelbaum, R.J. \& Carpentier, Y.A. (1992). Effects of essential fatty acid contents of lipide mulsions on erythrocyte polyunsaturated fatty acid composition in patients on long-term parenteral nutrition. Clinical Nutrition, Vol. 11, 262-268.

Lepage, G. \& Roy, C.C. (1986). Direct transesterification of all classes of lipids in a one step reaction. Journal of Lipid Research, Vol. 48, 2463-2470.

Zhang, Y. ; Bulur, N., Louchami, K., Hacquebard, M., Larondelle, Y., Carpentier, Y.A., Sener, A. \& Malaisse, W.J. (2010). The metabolic syndrome of $\omega 3$-depleted rats. IX. Food intake. The Open Physiology Journal, Vol. 3, 10-15.

Lowry, O.H. \& Passonneau, J.V. (1972). A flexible system of enzymatic analysis, Academic Press, New York, p. 174.

Leclercq-Meyer, V. ; Marchand, J., Woussen-Colle, M.C., Giroix, M.-H. \& Malaisse, W.J. (1985). Multiple effects of leucine on glucagon, insulin and somatostatin secretion from the perfused rat pancreas. Endocrinology, Vol. 116, 1168-1174.

Sener, A. ; Zhang, Y., Bulur, N., Louchami, K., Malaisse, W.J. \& Carpentier Y.A. (2009). . The metabolic syndrome of $\omega 3$-depleted rats. II. Body weight, adipose tissue mass and glycemic homeostasis. International Journal of Molecular Medicine, Vol. 24, 125-129.

Carpentier, Y.A.; Hacquebard, M., Zhang, J., Larondelle, Y., Portois, L. \& Malaisse, W.J. (2011b). The metabolic syndrome of $\omega 3$-depleted rats: dietary changes in lipid fatty acid pattern without changes in total lipid content. XV. Comprehensive view. Metabolic and Functional Research on Diabetes, Vol. 4 (suppl. 1), in press.

Malaisse, W.J.; Sener, A. \& Carpentier, Y.A. (2010). Plasma phospholipid-mediated transfer of docosahexaenoic acid from liver to brain phospholipids in Type 1 and Type 2 diabetic rats. Molecular Medicine Reports, Vol. 3, 977-981 


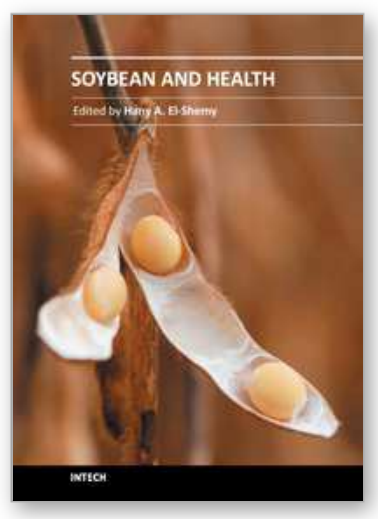

\author{
Soybean and Health \\ Edited by Prof. Hany El-Shemy
}

ISBN 978-953-307-535-8

Hard cover, 502 pages

Publisher InTech

Published online 12, September, 2011

Published in print edition September, 2011

Worldwide, soybean seed proteins represent a major source of amino acids for human and animal nutrition. Soybean seeds are an important and economical source of protein in the diet of many developed and developing countries. Soy is a complete protein, and soy-foods are rich in vitamins and minerals. Soybean protein provides all the essential amino acids in the amounts needed for human health. Recent research suggests that soy may also lower risk of prostate, colon and breast cancers as well as osteoporosis and other bone health problems, and alleviate hot flashes associated with menopause. This volume is expected to be useful for student, researchers and public who are interested in soybean.

\title{
How to reference
}

In order to correctly reference this scholarly work, feel free to copy and paste the following:

Willy J. Malaisse and Yvon A. Carpentier (2011). Effects of Soya Oil upon the Metabolic Syndrome of w3Depleted Rats, Soybean and Health, Prof. Hany El-Shemy (Ed.), ISBN: 978-953-307-535-8, InTech, Available from: http://www.intechopen.com/books/soybean-and-health/effects-of-soya-oil-upon-the-metabolic-syndromeof-3-depleted-rats

\section{INTECH}

open science | open minds

\section{InTech Europe}

University Campus STeP Ri Slavka Krautzeka 83/A 51000 Rijeka, Croatia

Phone: +385 (51) 770447

Fax: +385 (51) 686166 www.intechopen.com

\section{InTech China}

Unit 405, Office Block, Hotel Equatorial Shanghai No.65, Yan An Road (West), Shanghai, 200040, China 中国上海市延安西路65号上海国际贵都大饭店办公楼405单元 Phone: +86-21-62489820

Fax: +86-21-62489821 
(C) 2011 The Author(s). Licensee IntechOpen. This chapter is distributed under the terms of the Creative Commons Attribution-NonCommercialShareAlike-3.0 License, which permits use, distribution and reproduction for non-commercial purposes, provided the original is properly cited and derivative works building on this content are distributed under the same license. 